\title{
The role of heparanase and sulfatases in the modification of heparan sulfate proteoglycans within the tumor microenvironment and opportunities for novel cancer therapeutics
}

\author{
Edward Hammond ${ }^{1}$, Ashwani Khurana ${ }^{2}$, Viji Shridhar $^{2}$ and Keith Dredge ${ }^{1}$ * \\ 1 Progen Pharmaceuticals Ltd., Brisbane, QLD, Australia \\ ${ }^{2}$ Department of Experimental Pathology, Mayo Clinic College of Medicine, Rochester, MN, USA
}

\author{
Edited by: \\ Elvira V. Grigorieva, Institute of \\ Molecular Biology and Biophysics SB \\ RAMS, Russia \\ Reviewed by: \\ Stephan Von Gunten, University of \\ Bern, Switzerland \\ Daniel Christian Hoessli, International \\ Center for Chemical and Biological \\ Sciences, Switzerland \\ *Correspondence: \\ Keith Dredge, 2806 Ipswich Road, \\ Darra, QLD 4076, Australia \\ e-mail:keithd@progen-pharma.com
}

\begin{abstract}
Heparan sulfate proteoglycans (HSPGs) are an integral and dynamic part of normal tissue architecture at the cell surface and within the extracellular matrix. The modification of HSPGs in the tumor microenvironment is known to result not just in structural but also functional consequences, which significantly impact cancer progression. As substrates for the key enzymes sulfatases and heparanase, the modification of HSPGs is typically characterized by the degradation of heparan sulfate (HS) chains/sulfation patterns via the endo-6-O-sulfatases (Sulf1 and Sulf2) or by heparanase, an endo-glycosidase that cleaves the HS polymers releasing smaller fragments from HSPG complexes. Numerous studies have demonstrated how these enzymes actively influence cancer cell proliferation, signaling, invasion, and metastasis. The activity or expression of these enzymes has been reported to be modified in a variety of cancers. Such observations are consistent with the degradation of normal architecture and basement membranes, which are typically compromised in metastatic disease. Moreover, recent studies elucidating the requirements for these proteins in tumor initiation and progression exemplify their importance in the development and progression of cancer. Thus, as the influence of the tumor microenvironment in cancer progression becomes more apparent, the focus on targeting enzymes that degrade HSPGs highlights one approach to maintain normal tissue architecture, inhibit tumor progression, and block metastasis. This review discusses the role of these enzymes in the context of the tumor microenvironment and their promise as therapeutic targets for the treatment of cancer.
\end{abstract}

Keywords: heparanase, Sulf1, Sulf2, heparan sulfate, cancer therapy, tumor microenvironment targeting

\section{INTRODUCTION}

Heparan sulfate (HS) chains are an important component of the extracellular matrix (ECM) and they facilitate a number of important biological processes in health and disease. Incorporated into heparan sulfate proteoglycans (HSPG), they comprise a significant fraction of the complex and dynamic ECM and contribute to the biological roles of this medium. The functions of HSPG are varied: the maintenance of a 3D structural matrix for cell attachment; in certain cases the formation of barrier structures (basement membranes); the provision of a reservoir of biological signaling molecules; acting as a cofactor for signaling molecules binding to their receptors (1-3). These functions are modulated by proteins that are released into the ECM to modify its constituent molecules. Three important proteins within this category are heparanase (4-6), Sulf1, and Sulf2 $(7,8)$, which are released by a variety of cells to modify the structure of HS and thereby alter the function of the ECM.

This review will focus upon the roles of these three enzymes in modifying HS in the tumor microenvironment to facilitate processes that support or repress cancer growth and spread. The importance of heparanase, Sulf1, and Sulf2 will also be demonstrated by exploring their association with poor patient prognosis in clinical studies. Finally, the relevant therapeutic developments in the area will be summarized.

\section{ENZYME PROPERTIES HEPARANASE}

There is only one heparanase gene known in mammals (HPSE in humans) and it expresses a $65 \mathrm{kDa}$ precursor polypeptide that is enzymatically inactive. Proteolytic excision by cathepsin L of a 48 amino acid peptide yields an active heterodimer comprising 8 and $50 \mathrm{kDa}$ subunits. Although the structures of precursor and active heparanase are unknown, it has been postulated that the excised linker sequence occludes the active site based on sequence analysis and that once removed the active site is revealed allowing catalysis to proceed (9). Sequence homology modeling has indicated that heparanase contains a TIM barrel fold, which incorporates the two HS-binding regions (residues 158-162 and 270-280) and the catalytic residues (Glu225 and Glu343) of the active site (10-14). The $\mathrm{C}$ terminus of the protein forms a discrete domain, which 


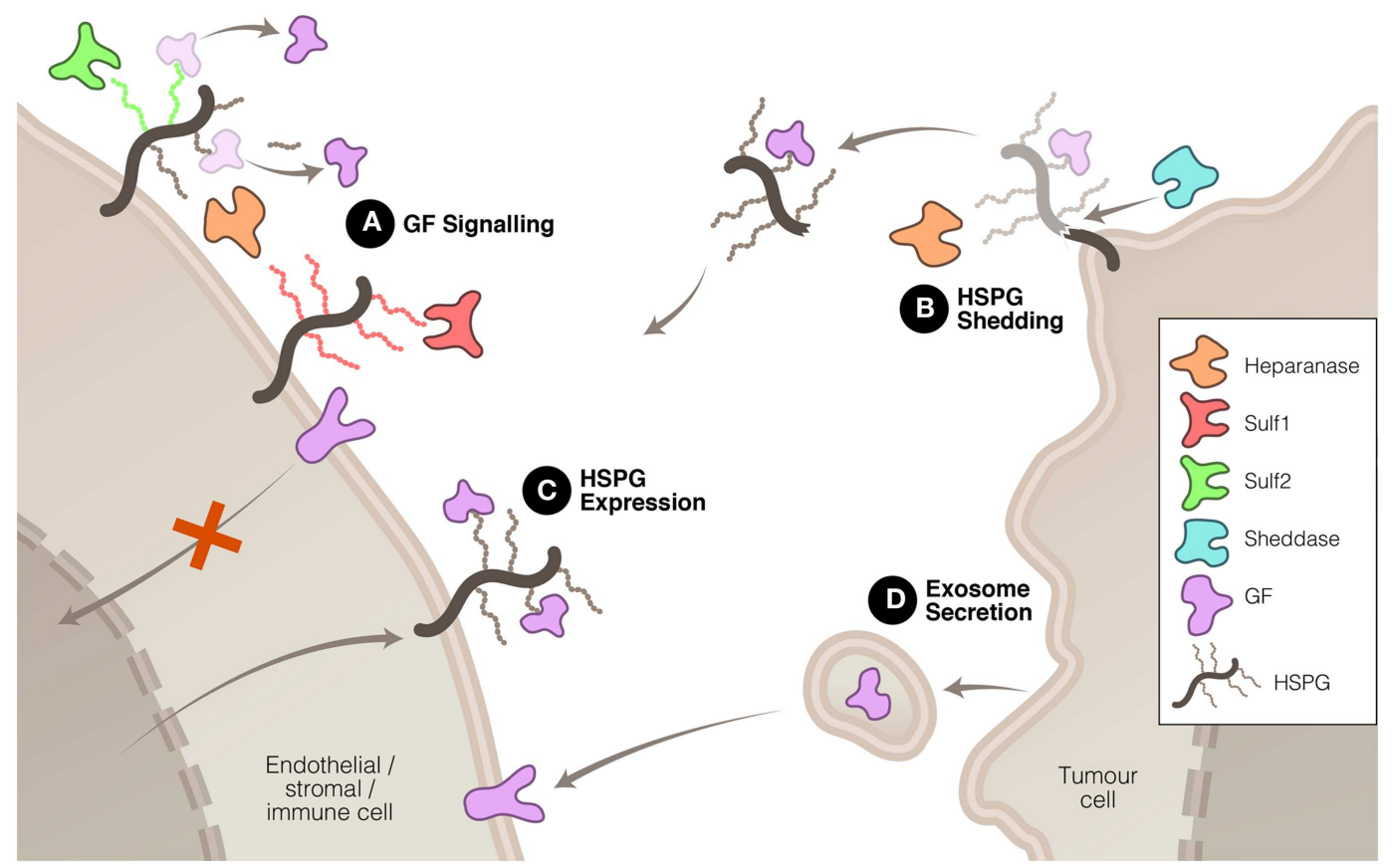

FIGURE 1 | Mechanisms whereby heparanase, Sulf1, and Sulf2 regulate HS function to promote or inhibit tumor growth and spread. (A) HS modification by these three enzymes can have promoting or inhibiting effects on growth factor (GF) signaling. (B) Heparanase, in association with sheddases, can stimulate HSPG shedding, dispersing autocrine to paracrine signaling. (C) Heparanase and Sulf2 can up-regulate HSPG expression to promote GF signaling. And (D) heparanase can induce exosome secretion allowing tumor cell communication with neighboring cells. has non-catalytic properties and is involved in a heparanasemediated signaling function that is distinct from its enzymatic activity $(15,16)$. This review will focus upon the enzymatic activity of heparanase and its role in regulating HS functioning in the ECM.

Catalytically, heparanase is an endo- $\beta$ glucuronidase that cleaves HS chains at a limited number of sites within HS chains yielding relatively large degradation fragments [5-10 kDa or $10-20$ sugar units (17)]. The exact substrate requirements for heparanase have not been clarified and recent studies suggest that it has alternating modes of catalysis (18), but it appears to favor trisaccharide sequences containing flanking glucosamine residues that are $\mathrm{N}$ - and 6-O sulfated (19). The $\mathrm{pH}$ optimum for heparanase catalysis peaks at 5 and the enzyme possesses little activity above 7 (20).

\section{SULF1 AND SULF2}

Sulf1 and Sulf2 are two closely related members of the sulfatase family (human genes SULF1 and SULF2). Unlike most other sulfatases, which are intracellular and function in the catabolism of sulfated molecules, Sulf1 and Sulf 2 are extracellularly targeted and function by selectively removing 6-O-sulfate groups from glucosamine residues within HS polymers. Like heparanase, the Sulfs are also expressed as precursor polypeptides $(125 \mathrm{kDa})$ and are processed by a furin-type protease to produce the mature heterodimer comprising 75 and $50 \mathrm{kDa}$ subunits connected by disulfide linkages $(21,22)$. Although the active site is contained in the $75 \mathrm{kDa}$ subunit, both subunits are required for activity. In contrast to heparanase, the pH optima for the Sulfs are 7-8 (23). Significantly, catalysis by either Sulf to remove 6-O-sulfates from
HS chains would reduce the affinity that heparanase has for these portions of the glycosaminoglycan. It is not clear, however, whether the Sulfs play a role in modulating heparanase activity and, thus, regulating its function in vivo.

\section{MOLECULAR PROCESSES IN TUMOR MICROENVIRONMENT}

Heparanase, Sulf1, and Sulf2 have been shown, by virtue of their enzymatic modification of the ECM, to affect the signaling of a number of proteins that are important drivers of tumor growth or progression. In some instances, the signaling function of heparanase may be involved in driving these changes, but it is accepted that heparanase cleavage of HS also plays a significant role in modulating signal transduction. These three enzymes accomplish this modulation in signaling in a number of ways (Figure 1). Firstly, heparanase and Sulf activity modifies the HS component of the ECM, thus altering the interactions between signaling molecules and their receptors. Secondly, heparanase is closely linked to the process of syndecan shedding, particularly syndecan-1, which can be important in changing the focus of a signaling stimulus, for example from autocrine to paracrine. Thirdly, heparanase and Sulf2 regulate expression of HSPG at the cell surface, thus promoting HS-dependant signaling. And fourthly, heparanase is involved in exosome formation by cancer cells, which has recently been shown to promote tumor progression by acting upon both cancerous and stromal cells.

\section{HS MODIFICATION TO MODULATE SIGNALING}

The modification of HS chains in the ECM to liberate stored signaling molecules in the tumor microenvironment is a mechanism that 
heparanase and the sulfatases have in common. There is, however, some diversity in the outcomes resulting from the modification of HS by these three enzymes. Heparanase cleavage of HS has been shown to increase the solubility of a variety of signaling molecules including VEGF $(24)$ and FGF2 $(25,26)$ thus increasing their access to receptors and facilitating signal transduction. This property has linked heparanase with the promotion of a number of pro-tumor processes including angiogenesis, cell proliferation and invasion, inhibition of apoptosis, and metastasis.

In addition to its catalysis resulting in increased availability of signaling molecules, heparanase cleavage of HSPG can also facilitate the interaction of these molecules with their receptors. Moderate heparanase activity has been shown to potentiate FGF2 signaling (27). This effect appears to be due to the solubilization of HS chains by heparanase as demonstrated by the observation that heparanase-cleaved HS chains stimulated FGF2 activity in the absence of heparanase itself. Soluble HS may improve the likelihood of formation of the active FGF2-FGFR-HS ternary complex by easing the conformational constraints of this assembly. A contrasting mechanism was discovered with lacritin in which heparanase promotes the activity of this mitogenic protein by removing the HS chains from syndecan-1 leaving the deglycanated HSPG as the active receptor for lacritin (28).

Rather than having uniformly tumor-promoting properties, Sulf1 and Sulf 2 have pro- and anti-tumor affects. Functionally, activity of both sulfatases is linked to angiogenesis, albeit in opposing manner. Despite their similar enzymatic activities, evidence suggests that Sulf1 and Sulf2 play opposing roles in the progression of tumors. For example, Sulf1 has been shown to attenuate the signaling of HS-binding growth factors such as FGF2 (29, 30), VEGF (30), amphiregulin (31), HB-EGF (29), and HGF (32, 33). Such effects are mediated by reduced affinity of these signaling proteins for vascular endothelial HS, thus reducing their concentration at the cell surface and minimizing interaction with their cognate receptors. Perhaps, the most studied example is the attenuation of FGF2 signaling by Sulf1. The removal of 6-O-sulfate groups by Sulf1 reduces formation of the active ternary FGF2-FGFRHS complex and consequently blocks FGF2 signaling $(34,35)$. However, the regulatory functions of Sulf1 have added complexity because alternative splicing of this gene can generate isoforms, which have different effects on Wnt signaling (36).

In contrast to Sulf1, Sulf2 has been shown to mobilize and increase the signaling of FGF2 in HCC cells (37). Interestingly, it accomplishes this despite having the same 6-O-endosulfatase activity as Sulf1 and despite the observed FGF2 signaling remaining HS dependant (37). Sulf2 has shown similar promotion of signaling with several other HS-binding signaling proteins including VEGF (38), Wnt (39, 40), SDF1 (38), and GDNF (41). Apart from the opposing roles played by Sulf1 and Sulf2 in regulating tumor growth through mobilizing heparan binding growth factors, these endosulfatases are also involved in regulating apoptotic proteins enhancing the sensitivity to chemotherapeutic agents in ovarian cancer. Recently, it was shown that Sulf1 depletion in ovarian cancer cells resulted in marked decrease in pro-apoptotic protein such as Bim, thus promoting tumor growth (42). Although reduction in Bim levels were attributed to high ERK activities, it underscores the possibility that lower levels of apoptotic proteins will favor resistance to chemotherapeutic agents. Along these lines, it was demonstrated that genetic silencing of Sulf1 in ovarian cancer cells attenuated cisplatin induced cytotoxicity (43). Consistent with their opposing roles in growth factor signaling, Sulf2 expression attenuated cell death induction by MEK, JNK, and PI3K inhibitors in hepatocellular carcinoma cell lines. These data were further strengthened by the finding that Sulf2 expression levels were elevated in human hepatocellular carcinoma (44). Overall, it is conceivable to conclude that Sulf1 plays anti-tumor roles whereas Sulf2 plays tumor-promoting roles in several tumor types. The paradox of how two sulfatases with similar catalytic activities have different biological functions and outcomes in tumor types, remains to be solved.

\section{SYNDECAN SHEDDING}

The expression and mobilization of HSPG, such as syndecan, in the tumor and stroma microenvironment is associated with poor prognosis in a number of cancers. Expressed at the cell surface, these proteoglycans can be shed by the action of proteases referred to as sheddases. The protein core of the syndecan HSPG is cleaved by proteases, such as MMP-9, releasing it from attachment to the cell membrane. Although sheddases are responsible for releasing syndecan from the cell surface, heparanase promotes this process in two ways: firstly, by degrading HS chains, it increases the rate at which sheddases cleave the core protein (45) and secondly, heparanase can increase the expression of sheddases such as MMP-9 (46). Shed syndecan, because it commonly contains bound signaling proteins, facilitates the translocation of these signals from the expressing cell, which may be a tumor cell, to stromal cells, thus converting autocrine signaling into a paracrine signal (47-49). It is noteworthy that shed syndecan ectodomain, which can be detected in sampled plasma or serum, represents a potential biomarker for the malignancy status of cancer (50) and its response to a heparanase-targeting therapeutic.

\section{HS UPREGULATION}

Both heparanase and Sulf2 are capable of increasing expression of HSPG targeted to the cell surface and, consequently, increasing pro-tumor signaling by HS-binding growth factors. Sulf2 has been shown to activate the Wnt pathway via upregulating glypican 3 at the cell surface, which results in enhanced Wnt-Frz complex formation and increased Wnt- $\beta$-catenin signaling (37, $39,51)$. Similarly, heparanase has been demonstrated to regulate the expression of syndecan-1 in multiple myeloma cells (52). Heparanase promotes the expression of this cell surface HSPG, which is involved in facilitating the transduction of a range of signaling pathways including FGF2 (53), Wnt (54), and HGF (55). Apart from exerting control over the total mass of HS, there is evidence to suggest that heparanase also affects the composition of the HS chains. Higher levels of heparanase expression correlated with increased $\mathrm{N}$ - and $\mathrm{O}$-sulfation of HS chains which lead to potentiation of FGF1 and FGF2 signaling (56).

\section{EXOSOME SECRETION}

Another mechanism, recently discovered, by which heparanase is able to promote tumor malignancy is via the stimulation of exosome secretion (57), although as yet Sulf1 and Sulf2 have not been shown to be involved in this process. Exosomes are lipid membrane bound extracellular vesicles that allow tumor cells to communicate 
with and co-opt neighboring cells to assist in modifying the tumor microenvironment and, thus, promote the tumor's growth and spread (58-60). Heparanase enzymatic activity has been shown to promote the formation of exosomes by several types of cancer cells and, moreover, to affect the molecular composition of the exosomes (57). The resulting exosomes were potent stimulators of both tumor and endothelial cells (Figure 1). The significance of this process in cancer has yet to be established but, if confirmed, would highlight the diversity of heparanase functions in tumor promotion.

\section{POTENT REGULATORS OF HS FUNCTION}

Heparanase, Sulf1, and Sulf2 drive a range of processes in the tumor microenvironment, many of which, in the case of heparanase and Sulf2 promote tumor malignancy, and some, in the case of Sulf1 inhibit malignancy. Despite their shared substrate and significance in cancer progression, it is important to note that the $\mathrm{pH}$ optima of heparanase $(\mathrm{pH} 5)$ and the Sulfs ( $\mathrm{pH} 7-8)$ preclude them from being at their most active in the same microenvironment compartment, or at the same time. The low extracellular $\mathrm{pH}$ associated with tumor-driven hypoxia has the consequence of stimulating heparanase-mediated activation of pro-angiogenic growth factors leading to a replenishment of the tumor microenvironment (61-63). Interestingly, Sulf1 and Sulf2 show the opposite environmental regulation being suppressed during hypoxia $(64,65)$. This is unsurprising for Sulf1, given its largely antagonistic function compared to heparanase. Sulf2, however, has pro-angiogenic properties like heparanase but is, nonetheless, downregulated under conditions requiring new blood supply. This apparent paradox suggests a complicated regulatory interaction between heparanase and the Sulfs. One could speculate that the Sulfs, with their neutral $\mathrm{pH}$ optimum and fine interplay between pro- and anti-angiogenic functions, are the early regulators of HS remodeling to control angiogenesis but, if metabolic changes or tumor growth drive the compartment into hypoxia, then heparanase becomes the leading regulator.

\section{CELLULAR PROCESSES}

For some time, the involvement of heparanase in the metastatic extravasation of tumor cells and invasion of immune cells has been known. We will not cover in detail the work describing the importance of heparanase in these processes but will instead refer the interested reader to the excellent reviews that have already summarized this data $(5,6,66)$. Rather, we will highlight one of the areas of research that has recently increased our understanding of heparanase functioning at the cellular level: namely its role in promoting epithelial-mesenchymal transition (EMT).

The transition of epithelial cells from their polarized state to non-polarized multipotent mesenchymal cells is an important process during metastasis. Recent studies examining EMT of kidney tubule epithelial cells into myofibroblasts show that heparanase is involved in driving this process by promoting FGF2 signaling (67). The mechanism whereby heparanase promotes this activity is not clear but it appears to involve enzymatic activity because the heparanase inhibitor sulodexide abrogates the effect (68). While these results were obtained using kidney tubule cells, it is intriguing to speculate that the heparanase-FGF2 axis plays an important role in cancer spread due to the well established connection between FGF2 and EMT in a variety of other situations, including tumor cells (69-72).

Given the role of FGF2 in heparanase-mediated EMT, it may be discovered that Sulfs also have roles in regulating EMT due to their interactions with this growth factor. In support of this, there is a recent finding that suppression of Sulf1, among other proteins, was associated with activation of EMT in HCC cells via increased signaling through the Akt and ERK pathways, which would be expected after Sulf1-mediated FGF2 inhibition was alleviated (73).

\section{CLINICAL ASSOCIATION STUDIES}

Reports identifying an association of heparanase, Sulf1, and/or Sulf2 expression or protein levels from clinical samples have been discussed in extensive detail in many excellent reviews $(7,8,66$, 74-76). Nevertheless, Table 1 highlights several recent studies, which have identified an association of these degrading extracellular enzymes of HS with tumor progression, metastasis, and poor prognosis, and illustrates some of the scientific and clinical findings in a variety of cancer types.

It has been postulated that heparanase and HSPGs act synergistically within the tumor microenvironment to enhance tumor growth and the enzymatic versus non-enzymatic roles of heparanase in cancer have been discussed elsewhere (74). Although the active form of heparanase has been identified as a key player in multiple myeloma (52) and sarcoma (77), several other studies have linked the overexpression of the active form with aggressive primary tumor growth, invasion, and metastasis in certain cancer types. In contrast, Sulf1 has been found to be downregulated in a number of cancer types while Sulf2 is typically overexpressed in carcinomas but importantly, these may be differentially expressed depending on the stage of cancer and the level of hypoxia in the tumor microenvironment (7). This section highlights some of the prevalent cancer types, which have reported significant alterations in heparanase, Sulf1, and/or Sulf2 and how these changes in expression correlate with indices of cancer progression such as prognostic indicators, tumor development, metastasis, and survival.

\section{SOLID TUMORS}

\section{PANCREATIC CANCER}

Overexpression of heparanase in pancreatic adenocarcinomas (PDAC) was identified several years ago when investigators discovered that this may facilitate cancer cell invasion and enhancement of metastatic dissemination (95). Postoperative survival correlated inversely with heparanase expression by tumors reflected by a median survival of 34 and 17 month for heparanase negative and positive tumors, respectively (96). Using RT-PCR and Western Blotting techniques, Chen and colleagues demonstrated that the expression of HPSE was significantly associated with TNM grade and invasion to nerves or lymph nodes although did not reveal a significant difference between histological differentiation and the tumor size (97). Even serum heparanase was found to be significantly elevated in PDAC patients (especially in those with heparanase positive tumors by IHC) and treatment with a small cohort of patients $(n=11)$ reduced heparanase levels by $64 \%$ after 2 weeks of treatment with gemcitabine (98). More recently, pancreatic neuroendocrine tumors (PNET) have now also been identified as a cancer type in which positive heparanase expression 
Table 1 | Association of heparanase, Sulf1, and Sulf2 in solid tumors and hematologic malignancies.

\begin{tabular}{|c|c|c|c|c|}
\hline Enzyme & Cancer & Key scientific finding & Key clinical finding & Reference \\
\hline Heparanase & PNET & $\begin{array}{l}\text { HPSE mRNA } \uparrow \text { by } 40 \text {-fold in primary } \\
\text { tumors and metastatic tumors compared } \\
\text { to normal islets }\end{array}$ & $\begin{array}{l}\text { HPSE mRNA was significantly upregulated in PNET } \\
\text { patients with primary tumors }\left({ }^{*} P=0.046, n=25\right) \text { and } \\
\text { liver metastases }\left({ }^{*} P=0.026, n=15\right) \text { compared to } \\
\text { normal islet samples from normal islets }(n=4)\end{array}$ & (78) \\
\hline Heparanase & OMM & $\begin{array}{l}\text { HPSE staining was positive in } 81 \% \text { of } \\
\text { tumors ( } 66 \text { of } 81 \text { patients) }\end{array}$ & $\begin{array}{l}\text { Median survival time and } 5 \text {-year survival rate were } \\
12 \text { months and } 7.0 \% \text { in the high-HPSE group, } \\
35 \text { months and } 36.4 \% \text { in the low-HPSE group, } \\
62 \text { months and } 53.3 \% \text { in the no-HPSE group ( } P=0.001)\end{array}$ & (79) \\
\hline Heparanase & Cervical & HPSE $\uparrow$ by $63 \%$ (38/60) patients by IHC & Significant correlation with tumor size and clinical stage & (80) \\
\hline Heparanase & Ovarian & $\begin{array}{l}\text { Median HPSE serum levels } 2.77,4.86 \text { and } \\
7.68 \mathrm{ng} / \mathrm{mL} \text { in control, benign and } \\
\text { malignant samples respectively }\end{array}$ & $\begin{array}{l}\text { Increased serum HPSE in ovarian cancer patients with } \\
\text { distant metastasis }(P<0.05) \\
\text { HPSE (in conjunction with Cathepsin L and MMP-9) } \\
\text { elevation possibly useful in determining extent of } \\
\text { metastasis before surgery }\end{array}$ & (81) \\
\hline Heparanase & Oral SCC & HPSE $\uparrow$ in $41 \%(19 / 46)$ & $\begin{array}{l}\text { Rate of HPSE expression closely related to tumor size, } \\
\text { tumor stage, lymphatic metastasis, distant metastasis, } \\
\text { pathological and histological stage }\end{array}$ & (82) \\
\hline Heparanase & Lung* & $\begin{array}{l}\text { Adenocarcinomas exhibited strong HPSE } \\
\text { expression by IHC }\end{array}$ & $\begin{array}{l}\text { Heparanase expression tended to correlate with tumor } \\
\text { node metastasis (TNM) staging in non-small cell lung } \\
\text { carcinoma }\end{array}$ & (83) \\
\hline Heparanase & $\mathrm{CCC}$ & $\begin{array}{l}\text { HPSE expression from } 47 \text { patient samples } \\
\text { was significantly associated with PDGFR } \alpha \\
\text { expression but not its ligand PDGF }\end{array}$ & $\begin{array}{l}\text { HPSE expression (mRNA) <35th percentile led to } \\
\text { median OS } 10.2 \text { months versus HPSE }>35 \text { th percentile } \\
\text { lead to median OS } 20.1 \text { months }\end{array}$ & (84) \\
\hline \multirow[t]{2}{*}{ Heparanase } & Ewing's sarcoma & $\begin{array}{l}49 \%(34 / 69) \text { Of the cases were scored as } \\
\text { low }(+1) \text { intensity while } 51 \%(35 / 69) \\
\text { exhibited a strong }(+2) \text { staining intensity }\end{array}$ & $\begin{array}{l}\text { HPSE staining was evident in all biopsies examined, } \\
\text { exhibiting a high }(+2) \text { staining extent (i.e., }>50 \% \text { of the } \\
\text { cells) in the majority }(91 \%) \text { of cases. Possible association } \\
\text { to tumor size }(P=0.07) \text {, strong staining in } 75 \% \text { of those } \\
\text { with large tumors }(>10 \mathrm{~cm})\end{array}$ & (77) \\
\hline & STS & $\begin{array}{l}\text { High-HPSE expression in } 29 \text { (52.7\%) } \\
\text { primary tumors and } 22 \text { specimens }(47.8 \%) \\
\text { in metastatic sites }\end{array}$ & $\begin{array}{l}\text { HPSE expression not correlative with tumor } \\
\text { aggressiveness, tumor recurrence or survival }\end{array}$ & (87) \\
\hline Heparanase & AML & $\begin{array}{l}\text { mRNA and/or protein expression of HPSE } \\
\text { revealed low HPSE in ALL (and CLL, NHL) } \\
\text { patients and a high expression level in } \\
\text { MM and AML patients, versus healthy } \\
\text { controls }\end{array}$ & $\begin{array}{l}\text { HPSE mRNA expression was significantly increased in } \\
14 / 15 \text { patient samples and genotype frequency } \\
\text { comparisons revealed a significant association with } \\
\text { rs } 4364254 \text { [chi2 ( } 2 \text { d.f.) }=6.226, P=0.044 \text { ] in AML } \\
\text { patients. HPSE gene mRNA expression was high in AML } \\
\text { patients }\end{array}$ & $(88,89)$ \\
\hline
\end{tabular}


Table 1 | Continued

\begin{tabular}{|c|c|c|c|c|}
\hline Enzyme & Cancer & Key scientific finding & Key clinical finding & Reference \\
\hline Sulf1 & Gastric & $\begin{array}{l}\text { Sulf1 expression } \uparrow \text { in tumor tissues } \\
(P=0.0002) \text { compared to normal mucosa }\end{array}$ & $\begin{array}{l}\text { Multivariate analysis found Sulf1 is an independent } \\
\text { prognostic }(P=0.01) \text { and lymph node metastasis } \\
\text { predictive factor ( } P=0.0003 \text { ) in large cohort of patients } \\
(450)\end{array}$ & (90) \\
\hline Sulf1 & Gastric & $\begin{array}{l}\text { Sulf1 protein expression } \downarrow \text { which is } \\
\text { discordant with mRNA findings }\end{array}$ & $\begin{array}{l}\text { Despite mRNA expression being } \uparrow \text { in } 30 \% \text { of samples, } \\
\text { protein expression } \downarrow \text { in } 70 \% \text { (14/20) of tumor samples }\end{array}$ & (91) \\
\hline Sulf2 & GBM & $\begin{array}{l}\text { Sulf2 may alter PDGFR } \alpha \\
\text { signaling/activation to promote } \\
\text { tumorigenesis }\end{array}$ & $\begin{array}{l}\text { Sulf2 expression } \uparrow \text { in proneural subtype of GBM ( } n=173 \text {, } \\
P<0.005) \text { and } \uparrow \text { using IHC in } 28 \text { subtyped GBMs } \\
\text { demonstrated that proneural and mesenchymal subtypes }\end{array}$ & $(92)$ \\
\hline Sulf2 & $\mathrm{MM}$ & $\begin{array}{l}\text { Sulf2 } \uparrow \text { in hyperdiploid group but } \downarrow \text { in } \\
\text { groups of patients with Cyclin D1 or MAF } \\
\text { translocations }\end{array}$ & $\begin{array}{l}\text { Sulf2 expression in primary MM cells linked to poor } \\
\text { prognosis in two independent large cohorts. Sulf2 was } \\
\text { independently predictive for OS ( } P=0.02)\end{array}$ & (93) \\
\hline Sulf2 & OAC/OSCC & $\begin{array}{l}\text { Sulf2 detected using IHC on } 75 \text { OAC } \\
\text { patients and } 25 \text { OSCC patients }\end{array}$ & $\begin{array}{l}\text { Majority of OAC and OSCC had Sulf2 staining. For every } \\
10 \%, \uparrow \text { in } \% \text { tumor cells staining for Sulf2, the HR for } \\
\text { death } \uparrow \text { by } 13 \%(P=0.03)\end{array}$ & (94) \\
\hline Sulf2 & Various & $\begin{array}{l}\text { Sulf2 increased }(P=0.001) \text { compared to } \\
\text { normal mucosa }\end{array}$ & $\begin{array}{l}\text { Significant overexpression in uveal melanoma }(=0.03) \text {, } \\
\text { lung adenocarcinoma }(P=0.04) \text { and colorectal carcinoma } \\
(P=0.001) \text { compared to low grade, low expressed and } \\
\text { colon adenomas respectively }\end{array}$ & (93) \\
\hline
\end{tabular}

AML, acute myeloid leukemia; CCC, cholangiocarcinoma; CLL, chronic lymphoblastic leukemia; DFS, disease-free survival; GBM, glioblastoma multiforme; HCC, hepatocellular carcinoma; HNSCC, head and neck squamous cell carcinoma; MM, multiple myeloma; NHL, non-Hodgkin's lymphoma; OAC, esophageal adenocarcinoma; OMM, oral mucosal melanoma; OSCC, esophageal squamous cell carcinoma; PNET, pancreatic neuroendocrine tumors; SCC, squamous cell carcinoma; STS, soft tissue sarcoma.

*37 Patients, there were 14 adenocarcinomas, 13 squamous cell carcinomas, 5 large cell carcinomas, and 5 small cell carcinomas.

was detected in patient tissue samples. Using tissue microarrays with samples from over 150 PNET patients, staining intensity of heparanase (by IHC) significantly correlated with tumor stage, higher tumor grade (as defined by tumor mitotic activity), and presence of distant metastasis (78).

Given the increasing understanding of the HS-binding protein interactome in pancreatic disease, enzymes involved in the degradation of proteoglycans such as HS may well play particularly important roles in neoplastic transformation of pancreatic cells. Although Sulf1 inhibits angiogenesis and tumorigenesis in vivo (30), a number of clinical studies have found that higher Sulf1 mRNA levels have been associated with tumor tissue compared to normal pancreas in relatively small cohorts of PDAC patients $(99,100)$. The finding that Sulf1 and Sulf2 can promote canonical Wnt signaling, a well described cascade in PDAC, suggests their overexpression is a contributory factor in relation to the growth and tumorigenicity of these pancreatic tumor cells (101). This appears to be in contrast to evidence that Sulfs block other pro-tumorigenic signaling pathways such as angiogenesis $(29,30,33,100)$, thus blocking tumor progression. However, the ability of Sulf1 to potentiate autocrine Wnt signaling in pancreatic cancer cells appears to be the key factor for tumors driven by this canonical signaling pathway (101). Taken together, heparanase, Sulf1, and Sulf 2 are enzymes which appear, at least in pancreatic cancer, to be positive regulators of tumor development.

\section{HEPATOCELLULAR CARCINOMA}

In patients undergoing hepatic resection, expression of heparanase mRNA was detected in $47 \%$ of HCCs and was significantly correlated with larger tumor size, presence of portal vein invasion, higher overall tumor invasiveness, and tumor microvessel density (MVD). Also, there was a direct correlation between the level of FGF2 protein and MVD in HCC tissue suggesting that heparanase enhances growth, invasion, and angiogenesis while FGF2 is a potent angiogenic factor for HCC (102). Interestingly, Sulf2 is known to increase FGF2 binding to HCC cells and upregulation of Sulf2 correlates with a worse prognosis in HCC patients (37). Chen and colleagues subsequently found a similar positive rate of increased expression of heparanase mRNA (48.5\%) in HCC tumors compared to surrounding parenchymal tissue. However, the positive rate increased to $71.4 \%$ in patients with a higher tendency of metastasis or recurrence compared with $31.6 \%$ in the group with a low tendency of metastasis or recurrence. The positive rate for mRNA heparanase in patients with metastasis/recurrence during postoperative follow-up $(78.6 \%, 11 / 14)$ was also significantly higher than that in those without metastatic recurrence $(21.4 \%, 3 / 14)$, indicating heparanase may be one of the reliable markers for metastatic activity in HCC (103). A follow-up study revealed heparanase expression was increased in patients with metastasis and was dependent on tumor staging with expression levels lower in clinical TNM stages I and II than in III and IV (104). Serum heparanase levels have also been reported to be higher in 
patients with large tumors $(>5 \mathrm{~cm}$ ), advanced pTNM stage (III and IV), tumor capsule absence, and portal vein invasion (105).

Although Sulf2 is purported to exhibit an oncogenic effect in HCC (37), in contrast, Sulf1 has been identified as having a tumor suppressor effect in $\operatorname{HCC}(32,106)$. However, in HCC tumor tissue, expression of Sulf1 is higher compared to adjacent benign tissues and approximately a third of HCCs express Sulf1 at high levels $>1.5 \times$ the level in adjacent benign tissue (107). Moreover, nearly $40 \%$ of patients with high tumor Sulf1 expression have the hepatoblast phenotype of HCC, which has relatively poor survival (108) and those with mid Sulf1 expression had a better survival outcome possibly due to the complex interaction of Sulf1 with antiand pro-tumorigenic signaling molecules, indicating a bimodal effect in HCC (107). In contrast, elevated Sulf2 is associated with a worse prognosis and a unimodal effect in HCC, causing activation of both tyrosine kinase and Wnt pathways (107). A different study also reported increased expression of Sulf2 in liver cancer specimens compared to normal tissue counterparts (93).

\section{GASTRIC CANCERS}

Rates of positive expression for heparanase mRNA in gastric cancer tissues $(31 / 63,49 \%)$ compared with adjacent normal tissue $(11 / 42,26 \%)$ was first reported by Endo and colleagues in 2001 (109). A follow-up study confirmed 79.5\% (35/44) positive expression in heparanase protein using immunohistochemistry and also reported significantly poorer prognosis than those without such expression (110). A number of subsequent studies confirmed the increase expression of mRNA or protein in gastric cancer correlated with invasion, metastasis, and/or poor survival outcomes (103, 111-115).

Higher expression of Sulf1 and Sulf 2 compared to normal mucosa has been reported in gastric cancer, with the expression of Sulf1 significantly correlated with higher recurrence rates and worse overall survival in patients. Multivariate analysis revealed that Sulf1 is an independent prognostic factor and lymph node metastasis predictive factor in these patients (90). However, Sulf1 protein expression has also been reported as being down regulated in gastric cancer tissues, which is discordant with mRNA overexpression in tumors previously reported by the same laboratory (91), thus, demonstrating the complexity in associating Sulf expression/activity with clinicopathological settings. Laboratory data reports would suggest that Sulf1 inhibits cell proliferation and invasion in human gastric cells (116) and suppresses cell growth while down regulating the pro-tumorigenic Hedgehog signaling pathway in these cells (117).

\section{HEAD AND NECK CANCERS}

Strong heparanase expression in primary tumors and lymph nodes was initially reported to be associated with prolonged disease-free progression in head and neck squamous cell carcinoma, HNSCC (85). Intriguingly, some years later the same group revealed cellular heparanase expression in late-stage HNSCCs was associated with prolonged overall survival and proposed that the proliferationreducing effect of high heparanase levels might outweigh the tumor-promoting effects of heparanase in advanced tumors (86). Despite raising the importance of tumor type, stage, and role of heparanase in particular tumor microenvironment, other groups also found heparanase expression to be linked to poor prognosis. Heparanase expression is induced in HNSCC and is associated with tumors larger in size, increased invasiveness, and reduced patient survival (118). In cancer of the salivary glands, Vlodavsky and colleagues demonstrated very significant differences between those with high expressing heparanase tumors and those with low or no positive staining in terms of overall survival (66). Despite a lack of studies investigating the possible clinical correlates for Sulf1 or Sulf2 in HNSCC, there is evidence demonstrating that Sulf1 re-expression, which diminishes cell surface HSPG sulfation, interferes with both FGF2 and HGF signaling in SCCHN (33) and that desulfation of the cell surface HSPG by Sulf1 in SCCHN plays an important role in the control of tumor development (33).

\section{BREAST AND OVARIAN CANCERS}

The role of heparanase and HS in breast cancer has been discussed comprehensively in a recent review (4) but emerging data continues to identify heparanase as a prognostic marker for tumor progression in breast cancer. For example, elevated heparanase expression was associated with the lymph node status, late clinical stages, a short overall survival, and a short relapse-free survival with the highest heparanase levels in breast cancer those with lymph node metastasis. In addition, the serum heparanase levels of patients with metastatic breast cancer were significantly higher than primary breast cancer patients (119). By contrast, Fernandez-Vega and colleagues did not find any significant differences between heparanase expression in tumors and healthy tissue. However, despite no significant difference in non-metastatic tumors, there was a change in metastatic relative to healthy tissue. Expression of heparanase determined in tissue arrays by immunohistochemistry revealed varying levels of heparanase in different patients (120). Nevertheless, laboratory studies now implicate heparanase in an invasive cell phenotype driven by the small GTPases: Rac1 and RhoA in brain metastatic breast cancer cells. These actions of heparanase on Racl and RhoA are mediated by GEF-H1, suggesting roles for heparanase in the initial events of BMBC pathogenesis, for example, cell adhesion, cytoskeletal dynamics, and cell extravasation, which are independent of its enzymatic activity (121). The clinical value of using heparanase, as a prognostic biomarker, in combination with MMP-9 and Cathepsin, was reported for determining the extent of ovarian cancer metastasis before surgery (81).

Both Sulf1 and Sulf2 were shown to be overexpressed at gene and protein levels in non-metastatic invasive ductal carcinomas although no significant differences could be detected in metastatic tumors (120). However, a recent review article highlighted the down regulation of Sulf1 in early stage ovarian tumors and metastatic breast cancer patients (7) while assessment of Sulf2 using a cohort of breast cancer patients found significant upregulation in autologous metastatic lesion compared with primary tumors (122). It is of interest to note that as intimated in the PDAC setting, the tumor type, the Sulf isoform (Sulf1 and/or Sulf2), and the predominant pathway (Wnt or FGF2) might result in opposing effects of Sulf's on tumor progression and metastasis (122).

Sulf1 has been shown to be markedly downregulated in ovarian cancer cell lines and $75 \%$ of ovarian cancer tumor tissues $(43,123)$. In addition, a transcription factor vHNF has been 
shown to suppress Sulf1 expression in clear cell carcinoma (123), whereas HIF-1 alpha have been shown to suppress Sulf1 transcription in breast cancer cell lines (64). A subsequent study showed that restoration of Sulf1 expression leads to decreased tumor growth, angiogenesis, and enhanced the efficacy of chemotherapeutic agents such as cisplatin (124). Tumor suppressive effects of Sulf1 are predominantly linked to its ability to decrease FGF2, HB-EGF, amphiregulin signaling in ovarian and breast cancer cells $(30,64,101)$. Decreased 6- $O$ sulfation of heparan sulfate due to increased Sulf1 activities can also be recapitulated or mimicked by downregulation of 6-O-sulfotransferases (HS6ST1 and HS6ST2). More recently, it has been shown that downregulation of HS6ST1 reduced the signaling of HS-binding EGF signaling leading to reduced expression of FGF 1, IL6, and IL8 (125) in ovarian cancer cell lines. These data lend further support to the notion that decreased 6-O sulfation of HS results in reduced formation of the receptor-HS-growth factor ternary complex thereby limiting the effect of extracellular growth factors. Clinically, it has been shown that Sulf1 expression is associated with increased diseasefree and overall survival in breast cancer (64). Similarly, analysis of 501 ovarian patients revealed that serous tumors with moderate to high levels of Sulf1 (127 of 186, 68\%) showed a trend toward improved survival as assessed by Kaplan-Meier survival analysis and log-rank test (123). These data confirm an in vitro finding indicating a tumor suppressor role of Sulf1.

\section{NON-SMALL CELL LUNG CANCER}

Recent studies have identified the overexpression of heparanase in non-small cell lung cancer (NSCLC) $(83,126)$. Widespread Sulf2 protein expression was identified in tumor cells of 10/10 surgical specimens of human lung squamous carcinomas and knockdown of Sulf2 was found to reduce the growth of lung cancer cells, inhibit autocrine Wnt signaling, and inhibit tumor progression in a mouse model of NSCLC (127). The authors concluded that not only should Sulf2 be considered as a potential biomarker of lung cancer but that its inhibition could be achievable via small molecule or biologic agents and thus should be considered as a therapeutic target in lung cancer.

\section{OTHER SOLID TUMORS}

For further examples of the studies that detail the clinical association studies with heparanase, readers are referred to several reviews $(6,74,75)$. Similarly, comprehensive reviews on Sulf1 and Sulf2 provide further details of these enzymes in different cancer types $(8,76)$. In addition, an over-representation of Sulf2 gene expression in skin cancer, colorectal carcinoma, testicular teratoma, and liver cancer compared to their normal tissue counterpart has been reported (93). Further investigations revealed that Sulf2 was significantly overexpressed in high grade uveal melanoma compared to low grade and in patients presenting colorectal carcinoma compared to benign colon adenoma (93).

\section{HEMATOLOGIC TUMORS \\ MYELOMA}

Of particular interest in the field is the role of heparanase in myeloma because its overexpression in the bone marrow environment was associated with a shorter event-free survival of patients with newly diagnosed myeloma treated with high-dose chemotherapy and stem cell transplantation (52). Heparanase enhances osteoclastogenesis and bone loss - a major cause of morbidity in patient with multiple myeloma - by shifting the differentiation potential of osteoblast progenitors from osteoclastogenesis to adipogenesis possibly via induction of the Wnt signaling pathway inhibitor DKK1 by both osteoblast progenitors and myeloma cells (128). Such effects on osteoclastogenesis and bone loss can occur, in part, as the result of a significant elevation in the expression and secretion of receptor activator of NF- $\kappa \mathrm{B}$ ligand (RANKL) by heparanase-expressing myeloma cells. Another possible mechanism for the pro-tumorigenic effects of heparanase in myeloma was recently elucidated in animal models, which revealed that heparanase enhances myeloma progression via CXCL10 downregulation (129). In addition to an association of heparanase with myeloma progression, Bret and colleagues discovered that Sulf2 expression in primary multiple myeloma cells were associated with a poor prognosis in two independent large cohorts of patients. It remained an independent predictor when considered together with conventional multiple myeloma prognosis factors (93).

\section{LEUKEMIA}

In mononuclear cells derived from various leukemias, heparanase mRNA was expressed in 14 of 15 acute myeloid leukemia (AML) samples. In contrast, cells derived from all 33 chronic lymphoblastic leukemia, all 7 non-Hodgkin's lymphoma, 7 of 8 chronic myeloid leukemia, and 6 of 8 acute lymphoblastic leukemia patients showed no detectable expression of the heparanase RNA. Heparanase protein was detected primarily within the cytoplasm of AML cells, indicating that the enzyme is produced and stored within the cytoplasm of myeloid cells, with limited expression on the cell surface (88). The low heparanase gene expression level in ALL patients and a high expression level in MM and AML patients were confirmed in a follow-up study (89). A clear correlation was found between heparanase mRNA expression level and three HPSE gene single nucleotide polymorphisms (SNPs - rs4693608, rs11099592, and rs4364254) among healthy individuals. These data suggested that certain HPSE gene SNPs contributes to basal heparanase gene expression and that alterations in this gene are an important determinant in the pathogenesis of hematological malignancies (89). Sulf1 gene expression has been noted to be increased in T prolymphocytic leukemia and AML (93).

\section{THERAPEUTIC OPPORTUNITIES HEPARANASE INHIBITORS}

The development of heparanase inhibitors have been reviewed elsewhere $(75,130,131)$ but Table 2 highlights the drug discovery and development projects initiated in the pursuit of heparanase inhibition and their current status. PI-88 is a mixture of highly sulfated oligosaccharides derived from Pichia holstii, NRRL Y-2448, which is a non-cleavable structural mimic of HS (132) and is currently progressing through clinical development as a dual anti-angiogenic and anti-metastatic agent. As such, it is known to inhibit angiogenesis by interfering with HS recognition by many angiogenic growth factors such as VEGF, FGF1, FGF2, in addition to inhibiting heparanase activity (133). 
Table 2 | Past and present drug discovery/development programs targeting heparanase in oncology

\begin{tabular}{|c|c|c|c|}
\hline Company & Compound & Development stage & $\begin{array}{l}\text { ClinicalTrials.gov } \\
\text { Identifier/Reference }\end{array}$ \\
\hline Medigen Biotechnology Corporation (Taiwan) & Muparfostat (PI-88) & Phase III (current) & NCT01402908 \\
\hline Momenta Pharmaceuticals (US) & Necuparanib (M402) & Phase I/II (current) & NCT01621243 \\
\hline Sigma Tau Pomezia (Italy) & Roneparstat (SST0001) & Phase I (current) & NCT01764880 \\
\hline Oxford Glycosciences (UK) & OGT2115 & Preclinical (discontinued) & $(131)$ \\
\hline Imclone Systems (US) & Compound $7 a$ & Preclinical (discontinued) & (138) \\
\hline \multirow[t]{2}{*}{ InSight Biopharmaceuticals (Israel) } & Compound 4 & Preclinical (discontinued) & (139) \\
\hline & Compounds 1, 6 & & $(140)$ \\
\hline Astra Zeneca (UK) & Antibodies & Late discovery (discontinued) & (143) \\
\hline Endotis Pharma (France) & EP80061 from EP-8000 series & Discovery/preclinical (discontinued) & $(14,144)$ \\
\hline Unknown (Shanghai Institute of Materia Medica, China) & JG3 (oligomannurarate sulfate) & Early preclinical & $(145,146)$ \\
\hline \multirow[t]{2}{*}{ RIKEN Discovery Research Institute (Japan) } & RK-682 & Discovery & $(147)$ \\
\hline & $\mathrm{KI}-105$ & Discovery & (148) \\
\hline
\end{tabular}

Notably, PI-88 has been shown to inhibit primary tumor growth of invasive rat mammary adenocarcinoma, metastasis, and reduced vascularity of these tumors (134) while demonstrating significant anti-tumor activity in the pancreatic neuroendocrine RIP2Tag2 model (135) and in models of leukemia (136). As the most advanced heparanase inhibitor, it is currently being trialed in a Phase III study as an adjuvant treatment for patients with hepatitis virus related hepatocellular carcinoma after surgical resection (137).

Heparan sulfate mimetics or glycol-split heparins are considered the most common therapeutic approach to create novel oncology agents with some others currently in early stage clinical development. PG545 is a synthetic, potent competitive inhibitor of heparanase (149) demonstrated to possess significant anti-tumor, anti-angiogenic, and anti-metastatic activity in a variety of animal models (150-152). This agent is currently being assessed in a Phase I trial for patients with advanced solid tumors (153). M402 is a rationally engineered, non-cytotoxic HS mimetic, designed to inhibit multiple factors implicated in tumor-host cell interactions, including VEGF, FGF2, SDF1 $\alpha$, P-selectin, and heparanase demonstrating anti-metastatic activity alone and in combination with cisplatin or docetaxel in the orthotropic 4T1 murine mammary carcinoma model (154). Necuparanib (M402) is current under investigation with nab-paclitaxel and gemcitabine in pancreatic cancer (155). Roneparstat (SST0001) is an N-acetylated, glycol-split heparin, which inhibits heparanase, downregulates HGF, VEGF, and MMP-9 expression and suppresses angiogenesis. Roneparstat also diminishes heparanase-induced shedding of syndecan-1, which is known to be a potent promoter of myeloma growth (156). Roneparstat is currently being tested in a Phase I trial for patients with advanced multiple myeloma (157). Oligommanurarate sulfate (JG3), a novel marine-derived oligosaccharide, was also reported as a heparanase inhibitor (145), but has yet to be progressed to the clinic (as defined by registration on www.clinicaltrials.gov).

Apart from HS mimetics, small molecule inhibitors, and neutralizing antibody programs were developed by various companies including Oxford Glycosciences $(158,159)$, Imclone Systems (138, 160), and InSight Biopharmaceuticals (139-142), but the candidates failed to reach clinical trials. Although the reasons for the limited progression through to clinical development are unknown, the lack of a crystal structure for the heparanase protein may have been one of the confounding issues. But, it is interesting to note that the induction of endoplasmic reticulum stress by chemotherapeutic reagents is involved in the enhanced invasion and migration ability of breast cancer cells and inhibition of heparanase (using one of these inhibitors, OGT2115) suppressed the invasion and migration ability of breast cancer cells. This provides a strong rationale for the development of heparanase-based therapeutics for the prevention of metastasis induced by chemotherapeutic reagents (161). The use of OGT2115 combined with cisplatin led to significant inhibition of cell proliferation, invasion, and migration of human nasopharyngeal cells, further suggesting that combination approaches with heparanase inhibitors may improve outcomes with existing chemotherapeutic regimens (162).

Recent discovery stage reports have identified new putative heparanase inhibitors but these continue to be classified 
as heparin derivatives or HS mimetics. TD4-143-1, which is a selectively sulfated tetrasaccharide containing unsubstituted glucosamine residues, which inhibited heparanase activity and suppressed invasion of breast cancer cells in vitro (163). Although not designed to specifically inhibit just heparanase, a newly synthesized hexasaccharide was considered to possess typical heparanase inhibition profile consistent with LMWHs and fondapariunx (164). Nevertheless, in both instances the anti-heparanase activity would be considered to be modest which perhaps limits the utility of such approaches in terms of preclinical or clinical development.

\section{SULFATASE MODULATORS}

In considering Sulf1 or Sulf2 as drug targets, the main consideration is the increasing evidence implicating the Sulfs in cancer and whether these are responsible for augmenting cancer cell growth or inhibiting it $(31,32,37,101,165)$. The HS mimetic PI-88 was demonstrated to inhibit the Sulfs with $\mathrm{IC}_{50}$ values in the range of $1.2-2.6 \mu \mathrm{g} / \mathrm{mL}$, which is comparable to that of heparanase (166). Although not specific for the Sulfs, the study suggested that inhibiting the Sulfs should be linked to an anti-tumor effect. However, it has been recently demonstrated that the loss of Sulf1 expression promotes tumorigenicity in ovarian cancer cells through regulating Bim expression (42). In gastric cancer cells, expression of Sulf1 significantly suppressed cellular proliferation possibly through abrogating the Hedgehog signaling pathway (117). In fact, the expression of Sulf1 mediated by adenovirus in liver carcinoma cells downregulates the activity of AKT and ERK signaling pathways, and inhibits HCC cell migration and proliferation, which makes it a candidate anti-tumor factor for cancer gene therapy (167). These data are corroborated by another recent study using microRNA miR-21 which suppressed Sulf1 and enhanced the activity of liver carcinoma cell proliferation and xenograft tumor growth in mouse models (73).

Conversely, silencing of Sulf2 expression in breast cancer cells attenuated ductal carcinoma in situ progression to invasive ductal carcinoma in vivo (168). Moreover, proteasomal inhibitors such as bortezomib abolished Sulf2 expression in multiple breast cancer cells (122). Consistent with these studies, a disulfonyl derivative of phenyl-tert-butyl nitrone (PBN) called OKN-007 was shown to inhibit Sulf2 activities in hepatocellular carcinoma cell lines although its activity against Sulf1 has not been assessed. OKN007 effectively inhibited tumor growth in HCC derived tumor xenografts exhibiting Sulf2 expression (169). Taken together, these studies suggest that while inhibiting Sulf2 may exert anti-tumor activities, the modulation of Sulf1 may have a divergent impact on tumor progression and be highly dependent on the tumor type and the key signaling pathways (e.g., Wnt) characterized to promote cell proliferation and survival in these tumors. Thus, significant inroads need to be made in researching the Sulfs as an appropriate target in cancer and identifying the optimal approaches needed to modulate their expression and activity in cancer.

\section{CONCLUSION}

The modification of HSPG in the tumor microenvironment modulates a variety of processes that are important in cancer growth and spread. Three enzymes - heparanase, Sulf1 and Sulf2 - play crucial roles in regulating HSPG functioning in this compartment and the up- and down-regulation of these proteins in a large variety of cancers demonstrates how important they are in promoting or repressing malignancy. While the involvement of heparanase in progressing tumors is well-documented, both at the mechanistic level and in clinical observations, the roles of the Sulfs are not so clear, particularly for Sulf1. This clarity is reflected in the more advanced stage of clinical development that anti-heparanase therapeutics has reached in comparison to Sulf inhibitors. Resolution of the pro- and anti-tumor properties of the Sulfs and how these relate to tumor-stromal relationships, primary and metastatic lesion interactions, and other aspects of tumor growth is required before the development of anti-Sulf therapeutics can proceed with confidence. Nevertheless, there is a substantial body of data describing the importance of heparanase, Sulf1, and Sulf2 in modulating HS functioning in cancer, which highlights the already well founded view that targeting the ability of tumors to modify their microenvironment in order to promote growth and spread represents a solid therapeutic development pathway.

\section{REFERENCES}

1. Kim S-H, Turnbull J, Guimond S. Extracellular matrix and cell signalling: the dynamic cooperation of integrin, proteoglycan and growth factor receptor. $J$ Endocrinol (2011) 209:139-51. doi:10.1530/JOE-10-0377

2. Szatmári T, Dobra K. The role of syndecan-1 in cellular signaling and its effects on heparan sulfate biosynthesis in mesenchymal tumors. Front Oncol (2013) 3:310. doi:10.3389/fonc.2013.00310

3. Barbouri D, Afratis N, Gialeli C, Vynios DH, Theocharis AD, Karamanos NK. Syndecans as modulators and potential pharmacological targets in cancer progression. Front Oncol (2014) 4:4. doi:10.3389/fonc.2014.00004

4. Gomes AM, Stelling MP, Pavão MSG. Heparan sulfate and heparanase as modulators of breast cancer progression. Biomed Res Int (2013) 2013:852093. doi:10.1155/2013/852093

5. Ramani VC, Purushothaman A, Stewart MD, Thompson CA, Vlodavsky I, Au JL-S, et al. The heparanase/syndecan-1 axis in cancer: mechanisms and therapies. FEBS J (2013) 280:2294-306. doi:10.1111/febs.12168

6. Masola V, Secchi MF, Gambaro G, Onisto M. Heparanase as a target in cancer therapy. Curr Cancer Drug Targets (2014) 14:286-93. doi:10.2174/ 1568009614666140224155124

7. Khurana A, Beleford D, He X, Chien J, Shridhar V. Role of heparan sulfatases in ovarian and breast cancer. Am J Cancer Res (2013) 3:34-45.

8. Vivès RR, Seffouh A, Lortat-Jacob H. Post-synthetic regulation of HS structure: the Yin and Yang of the Sulfs in cancer. Front Oncol (2014) 3:331. doi:10.3389/fonc.2013.00331

9. Abboud-Jarrous G, Atzmon R, Peretz T, Palermo C, Gadea BB, Joyce JA, et al. Cathepsin $\mathrm{L}$ is responsible for processing and activation of proheparanase through multiple cleavages of a linker segment. J Biol Chem (2008) 283:18167-76. doi:10.1074/jbc.M801327200

10. Hulett MD, Hornby JR, Ohms SJ, Zuegg J, Freeman C, Gready JE, et al. Identification of active-site residues of the pro-metastatic endoglycosidase heparanase. Biochemistry (2000) 39:15659-67. doi:10.1021/bi002080p

11. Levy-Adam F, Abboud-Jarrous G, Guerrini M, Beccati D, Vlodavsky I, Ilan N. Identification and characterization of heparin/heparan sulfate binding domains of the endoglycosidase heparanase. J Biol Chem (2005) 280:20457-66. doi:10.1074/jbc.M414546200

12. Zhou Z, Bates M, Madura JD. Structure modeling, ligand binding, and binding affinity calculation (LR-MM-PBSA) of human heparanase for inhibition and drug design. Proteins (2006) 65:580-92. doi:10.1002/prot.21065

13. Gandhi NS, Freeman C, Parish CR, Mancera RL. Computational analyses of the catalytic and heparin-binding sites and their interactions with glycosaminoglycans in glycoside hydrolase family 79 endo- $\beta$-D-glucuronidase (heparanase). Glycobiology (2012) 22:35-55. doi:10.1093/glycob/cwr095 
14. Sapay N, Cabannes E, Petitou M, Imberty A. Molecular model of human heparanase with proposed binding mode of a heparan sulfate oligosaccharide and catalytic amino acids. Biopolymers (2012) 97:21-34. doi:10.1002/bip.21696

15. Gingis-Velitski S, Zetser A, Flugelman MY, Vlodavsky I, Ilan N. Heparanase induces endothelial cell migration via protein kinase B/Akt activation. J Biol Chem (2004) 279:23536-41. doi:10.1074/jbc.M400554200

16. Ben-Zaken O, Gingis-Velitski S, Vlodavsky I, Ilan N. Heparanase induces Akt phosphorylation via a lipid raft receptor. Biochem Biophys Res Commun (2007) 361:829-34. doi:10.1016/j.bbrc.2007.06.188

17. Vreys V, David G. Mammalian heparanase: what is the message? J Cell Mol Med (2007) 11:427-52. doi:10.1111/j.1582-4934.2007.00039.x

18. Peterson S, Liu J. Deciphering mode of action of heparanase using structurally defined oligosaccharides. J Biol Chem (2012) 287:34836-43. doi:10.1074/jbc. M112.390161

19. Okada Y, Yamada S, Toyoshima M, Dong J, Nakajima M, Sugahara K. Structural recognition by recombinant human heparanase that plays critical roles in tumor metastasis. Hierarchical sulfate groups with different effects and the essential target disulfated trisaccharide sequence. J Biol Chem (2002) 277:42488-95. doi:10.1074/jbc.M206510200

20. Freeman C, Parish CR. Human platelet heparanase: purification, characterization and catalytic activity. Biochem J (1998) 330(Pt 3):1341-50.

21. Tang R, Rosen SD. Functional consequences of the subdomain organization of the sulfs. J Biol Chem (2009) 284:21505-14. doi:10.1074/jbc.M109.028472

22. Nagamine S, Keino-Masu K, Shiomi K, Masu M. Proteolytic cleavage of the rat heparan sulfate 6-O-endosulfatase SulfFP2 by furin-type proprotein convertases. Biochem Biophys Res Commun (2010) 391:107-12. doi:10.1016/j.bbrc. 2009.11.011

23. Morimoto-Tomita M, Uchimura K, Werb Z, Hemmerich S, Rosen SD. Cloning and characterization of two extracellular heparin-degrading endosulfatases in mice and humans. J Biol Chem (2002) 277:49175-85. doi:10.1074/jbc. M205131200

24. Tan KW, Chong SZ, Wong FHS, Evrard M, Tan SM-L, Keeble J, et al. Neutrophils contribute to inflammatory lymphangiogenesis by increasing VEGF-A bioavailability and secreting VEGF-D. Blood (2013) 122:3666-77. doi:10.1182/ blood-2012-11-466532

25. Elkin M, Ilan N, Ishai-Michaeli R, Friedmann Y, Papo O, Pecker I, et al. Heparanase as mediator of angiogenesis: mode of action. FASEB J (2001) 15:1661-3. doi:10.1096/fj.00-0895fje

26. Myler HA, West JL. Heparanase and platelet factor-4 induce smooth muscle cell proliferation and migration via bFGF release from the ECM. $J$ Biochem (2002) 131:913-22. doi:10.1093/oxfordjournals.jbchem.a003182

27. Reiland J, Kempf D, Roy M, Denkins Y, Marchetti D. FGF2 binding, signaling, and angiogenesis are modulated by heparanase in metastatic melanoma cells. Neoplasia (2006) 8:596-606. doi:10.1593/neo.06244

28. Ma P, Beck SL, Raab RW, McKown RL, Coffman GL, Utani A, et al. Heparanase deglycanation of syndecan-1 is required for binding of the epithelial-restricted prosecretory mitogen lacritin. J Cell Biol (2006) 174:1097-106. doi:10.1083/ jcb. 200511134

29. Lai J, Chien J, Staub J, Avula R, Greene EL, Matthews TA, et al. Loss of HSulf-1 up-regulates heparin-binding growth factor signaling in cancer. $J$ Biol Chem (2003) 278:23107-17. doi:10.1074/jbc.M302203200

30. Narita K, Staub J, Chien J, Meyer K, Bauer M, Friedl A, et al. HSulf-1 inhibits angiogenesis and tumorigenesis in vivo. Cancer Res (2006) 66:6025-32. doi:10.1158/0008-5472.CAN-05-3582

31. Narita K, Chien J, Mullany SA, Staub J, Qian X, Lingle WL, et al. Loss of HSulf-1 expression enhances autocrine signaling mediated by amphiregulin in breast cancer. J Biol Chem (2007) 282:14413-20. doi:10.1074/jbc.M611395200

32. Lai J-P, Chien JR, Moser DR, Staub JK, Aderca I, Montoya DP, et al. hSulf1 sulfatase promotes apoptosis of hepatocellular cancer cells by decreasing heparin-binding growth factor signaling. Gastroenterology (2004) 126:231-48. doi:10.1053/j.gastro.2003.09.043

33. Lai J-P, Chien J, Strome SE, Staub J, Montoya DP, Greene EL, et al. HSulf-1 modulates HGF-mediated tumor cell invasion and signaling in head and neck squamous carcinoma. Oncogene (2004) 23:1439-47. doi:10.1038/sj.onc. 1207258

34. Ishihara M, Takano R, Kanda T, Hayashi K, Hara S, Kikuchi H, et al. Importance of 6-O-sulfate groups of glucosamine residues in heparin for activation of FGF-1 and FGF-2. J Biochem (1995) 118:1255-60.
35. Pye DA, Vives RR, Turnbull JE, Hyde P, Gallagher JT. Heparan sulfate oligosaccharides require 6-O-sulfation for promotion of basic fibroblast growth factor mitogenic activity. J Biol Chem (1998) 273:22936-42. doi:10.1074/jbc.273.36. 22936

36. Sahota AP, Dhoot GK. A novel SULF1 splice variant inhibits Wnt signalling but enhances angiogenesis by opposing SULF1 activity. Exp Cell Res (2009) 315:2752-64. doi:10.1016/j.yexcr.2009.06.029

37. Lai J-P, Sandhu DS, Yu C, Han T, Moser CD, Jackson KK, et al. Sulfatase 2 up-regulates glypican 3, promotes fibroblast growth factor signaling, and decreases survival in hepatocellular carcinoma. Hepatology (2008) 47:1211-22. doi:10.1002/hep.22202

38. Uchimura K, Morimoto-Tomita M, Bistrup A, Li J, Lyon M, Gallagher J, et al. HSulf-2, an extracellular endoglucosamine-6-sulfatase, selectively mobilizes heparin-bound growth factors and chemokines: effects on VEGF, FGF-1, and SDF-1. BMC Biochem (2006) 7:2. doi:10.1186/1471-2091-7-2

39. Gao W, Ho M. The role of glypican-3 in regulating Wnt in hepatocellular carcinomas. Cancer Rep (2011) 1:14-9.

40. Nakamura I, Fernandez-Barrena MG, Ortiz-Ruiz MC, Almada LL, Hu C, Elsawa SF, et al. Activation of the transcription factor GLI1 by WNT signaling underlies the role of SULFATASE 2 as a regulator of tissue regeneration. J Biol Chem (2013) 288:21389-98. doi:10.1074/jbc.M112.443440

41. Ai X, Kitazawa T, Do A-T, Kusche-Gullberg M, Labosky PA, Emerson CP. SULF1 and SULF2 regulate heparan sulfate-mediated GDNF signaling for esophageal innervation. Development (2007) 134:3327-38. doi:10.1242/dev.007674

42. He X, Khurana A, Roy D, Kaufmann S, Shridhar V. Loss of HSulf-1 expression enhances tumorigenicity by inhibiting Bim expression in ovarian cancer. Int J Cancer (2014). doi:10.1002/ijc.28818

43. Staub J, Chien J, Pan Y, Qian X, Narita K, Aletti G, et al. Epigenetic silencing of HSulf-1 in ovarian cancer:implications in chemoresistance. Oncogene (2007) 26:4969-78. doi:10.1038/sj.onc.1210300

44. Lai J-P, Oseini AM, Moser CD, Yu C, Elsawa SF, Hu C, et al. The oncogenic effect of sulfatase 2 in human hepatocellular carcinoma is mediated in part by glypican 3-dependent Wnt activation. Hepatology (2010) 52:1680-9. doi:10.1002/hep.23848

45. Yang Y, Macleod V, Miao H-Q, Theus A, Zhan F, Shaughnessy JD, et al. Heparanase enhances syndecan-1 shedding: a novel mechanism for stimulation of tumor growth and metastasis. J Biol Chem (2007) 282:13326-33. doi:10.1074/jbc.M611259200

46. Purushothaman A, Chen L, Yang Y, Sanderson RD. Heparanase stimulation of protease expression implicates it as a master regulator of the aggressive tumor phenotype in myeloma. J Biol Chem (2008) 283:32628-36. doi:10.1074/jbc. M806266200

47. Seidel C, Børset M, Hjertner O, Cao D, Abildgaard N, Hjorth-Hansen H, et al. High levels of soluble syndecan-1 in myeloma-derived bone marrow: modulation of hepatocyte growth factor activity. Blood (2000) 96:3139-46.

48. Su G, Blaine SA, Qiao D, Friedl A. Shedding of syndecan-1 by stromal fibroblasts stimulates human breast cancer cell proliferation via FGF2 activation. $J$ Biol Chem (2007) 282:14906-15. doi:10.1074/jbc.M611739200

49. Purushothaman A, Uyama T, Kobayashi F, Yamada S, Sugahara K, Rapraeger AC, et al. Heparanase-enhanced shedding of syndecan-1 by myeloma cells promotes endothelial invasion and angiogenesis. Blood (2010) 115:2449-57. doi:10.1182/blood-2009-07-234757

50. Szarvas T, Reis H, Kramer G, Shariat SF, Vom Dorp F, Tschirdewahn S, et al. Enhanced stromal syndecan-1 expression is an independent risk factor for poor survival in bladder cancer. Hum Pathol (2014) 45:674-82. doi:10.1016/j.humpath.2013.10.036

51. Lai J-P, Sandhu DS, Yu C, Moser CD, Hu C, Shire AM, et al. Sulfatase 2 protects hepatocellular carcinoma cells against apoptosis induced by the PI3K inhibitor LY294002 and ERK and JNK kinase inhibitors. Liver Int (2010) 30:1522-8. doi:10.1111/j.1478-3231.2010.02336.x

52. Mahtouk K, Hose D, Raynaud P, Hundemer M, Jourdan M, Jourdan E, et al. Heparanase influences expression and shedding of syndecan-1, and its expression by the bone marrow environment is a bad prognostic factor in multiple myeloma. Blood (2007) 109:4914-23. doi:10.1182/blood-2006-08-043232

53. Filla MS, Dam P, Rapraeger AC. The cell surface proteoglycan syndecan-1 mediates fibroblast growth factor-2 binding and activity. J Cell Physiol (1998) 174:310-21. doi:10.1002/(SICI) 1097-4652(199803)174:3<310:AID-JCP5>3. $0 . \mathrm{CO} ; 2-\mathrm{R}$ 
54. Alexander CM, Reichsman F, Hinkes MT, Lincecum J, Becker KA, Cumberledge $\mathrm{S}$, et al. Syndecan-1 is required for Wnt-1-induced mammary tumorigenesis in mice. Nat Genet (2000) 25:329-32. doi:10.1038/77108

55. Derksen PWB, Keehnen RMJ, Evers LM, van Oers MHJ, Spaargaren M, Pals ST. Cell surface proteoglycan syndecan-1 mediates hepatocyte growth factor binding and promotes Met signaling in multiple myeloma. Blood (2002) 99:1405-10. doi:10.1182/blood.V99.4.1405

56. Escobar Galvis ML, Jia J, Zhang X, Jastrebova N, Spillmann D, Gottfridsson E, et al. Transgenic or tumor-induced expression of heparanase upregulates sulfation of heparan sulfate. Nat Chem Biol (2007) 3:773-8. doi:10.1038/nchembio. 2007.41

57. Thompson CA, Purushothaman A, Ramani VC, Vlodavsky I, Sanderson RD. Heparanase regulates secretion, composition, and function of tumor cellderived exosomes. J Biol Chem (2013) 288:10093-9. doi:10.1074/jbc.C112. 444562

58. Record M, Carayon K, Poirot M, Silvente-Poirot S. Exosomes as new vesicular lipid transporters involved in cell-cell communication and various pathophysiologies. Biochim Biophys Acta (2014) 1841:108-20. doi:10.1016/j.bbalip.2013. 10.004

59. Ge R, Tan E, Sharghi-Namini S, Asada HH. Exosomes in cancer microenvironment and beyond: have we overlooked these extracellular messengers? Cancer Microenviron (2012) 5:323-32. doi:10.1007/s12307-012-0110-2

60. Atay S, Godwin AK. Tumor-derived exosomes: a message delivery system for tumor progression. Commun Integr Biol (2014) 7:e28231. doi:10.4161/cib. 28231

61. He X, Brenchley PEC, Jayson GC, Hampson L, Davies J, Hampson IN. Hypoxia increases heparanase-dependent tumor cell invasion, which can be inhibited by antiheparanase antibodies. Cancer Res (2004) 64:3928-33. doi:10.1158/0008-5472.CAN-03-2718

62. Naomoto Y, Gunduz M, Takaoka M, Okawa T, Gunduz E, Nobuhisa T, et al. Heparanase promotes angiogenesis through Cox-2 and HIFlalpha. Med Hypotheses (2007) 68:162-5. doi:10.1016/j.mehy.2006.03.055

63. Wu W, Pan C, Meng K, Zhao L, Du L, Liu Q, et al. Hypoxia activates heparanase expression in an NF-kappaB dependent manner. Oncol Rep (2010) 23:255-61. doi:10.3892/or_00000631

64. Khurana A, Liu P, Mellone P, Lorenzon L, Vincenzi B, Datta K, et al. HSulf-1 modulates FGF2- and hypoxia-mediated migration and invasion of breast cancer cells. Cancer Res (2011) 71:2152-61. doi:10.1158/0008-5472. CAN-10-3059

65. Khurana A, Tun HW, Marlow L, Copland JA, Dredge K, Shridhar V. Hypoxia negatively regulates heparan sulfatase 2 expression in renal cancer cell lines. Mol Carcinog (2012) 51:565-75. doi:10.1002/mc.20824

66. Vlodavsky I, Beckhove P, Lerner I, Pisano C, Meirovitz A, Ilan N, et al. Significance of heparanase in cancer and inflammation. Cancer Microenviron (2012) 5:115-32. doi:10.1007/s12307-011-0082-7

67. Masola V, Gambaro G, Tibaldi E, Brunati AM, Gastaldello A, D’Angelo A, et al. Heparanase and syndecan-1 interplay orchestrates fibroblast growth factor-2induced epithelial-mesenchymal transition in renal tubular cells. J Biol Chem (2012) 287:1478-88. doi:10.1074/jbc.M111.279836

68. Masola V, Onisto M, Zaza G, Lupo A, Gambaro G. A new mechanism of action of sulodexide in diabetic nephropathy: inhibits heparanase-1 and prevents FGF-2-induced renal epithelial-mesenchymal transition. J Transl Med (2012) 10:213. doi:10.1186/1479-5876-10-213

69. Lee JG, Kay EP. NF- $\mathrm{B}$ is the transcription factor for FGF-2 that causes endothelial mesenchymal transformation in cornea. Invest Ophthalmol Vis Sci (2012) 53:1530-8. doi:10.1167/iovs.11-9102

70. Shirakihara T, Kawasaki T, Fukagawa A, Semba K, Sakai R, Miyazono K, et al. Identification of integrin $\alpha 3$ as a molecular marker of cells undergoing epithelial-mesenchymal transition and of cancer cells with aggressive phenotypes. Cancer Sci (2013) 104:1189-97. doi:10.1111/cas.12220

71. Chen J, Chen G, Yan Z, Guo Y, Yu M, Feng L, et al. TGF- $\beta 1$ and FGF2 stimulate the epithelial-mesenchymal transition of HERS cells through a MEKdependent mechanism. J Cell Physiol (2014). doi:10.1002/jcp.24610

72. Hu Y, Mintz A, Shah SR, Quinones-Hinojosa A, Hsu W. The FGFR/MEK/ ERK/brachyury pathway is critical for chordoma cell growth and survival. Carcinogenesis (2014) 35:1491-9. doi:10.1093/carcin/bgu014

73. Bao L, Yan Y, Xu C, Ji W, Shen S, Xu G, et al. MicroRNA-21 suppresses PTEN and hSulf-1 expression and promotes hepatocellular carcinoma progression through AKT/ERK pathways. Cancer Lett (2013) 337:226-36. doi:10.1016/j. canlet.2013.05.007

74. Vlodavsky I, Elkin M, Ilan N. Impact of heparanase and the tumor microenvironment on cancer metastasis and angiogenesis: basic aspects and clinical applications. Rambam Maimonides Med J (2011) 2:e0019. doi:10.5041/RMMJ. 10019

75. Pisano C, Vlodavsky I, Ilan N, Zunino F. The potential of heparanase as a therapeutic target in cancer. Biochem Pharmacol (2014) 89:12-9. doi:10.1016/j.bcp. 2014.02.010

76. Rosen SD, Lemjabbar-Alaoui H. Sulf-2: an extracellular modulator of cell signaling and a cancer target candidate. Expert Opin Ther Targets (2010) 14:935-49. doi:10.1517/14728222.2010.504718

77. Shafat I, Ben-Arush MW, Issakov J, Meller I, Naroditsky I, Tortoreto M, et al. Pre-clinical and clinical significance of heparanase in Ewing's sarcoma. J Cell Mol Med (2011) 15:1857-64. doi:10.1111/j.1582-4934.2010.01190.x

78. Hunter KE, Palermo C, Kester JC, Simpson K, Li J-P, Tang LH, et al. Heparanase promotes lymphangiogenesis and tumor invasion in pancreatic neuroendocrine tumors. Oncogene (2014) 33:1799-808. doi:10.1038/onc.2013.142

79. Wang X, Wen W, Wu H, Chen Y, Ren G, Guo W. Heparanase expression correlates with poor survival in oral mucosal melanoma. Med Oncol (2013) 30:633. doi:10.1007/s12032-013-0633-5

80. Zeng C, Ke Z-F, Luo W-R, Yao Y-H, Hu X-R, Jie W, et al. Heparanase overexpression participates in tumor growth of cervical cancer in vitro and in vivo. Med Oncol (2013) 30:403. doi:10.1007/s12032-012-0403-9

81. Zhang W, Yang H-C, Wang Q, Yang Z-J, Chen H, Wang S-M, et al. Clinical value of combined detection of serum matrix metalloproteinase-9, heparanase, and cathepsin for determining ovarian cancer invasion and metastasis. Anticancer Res (2011) 31:3423-8.

82. Xia F, Xu JC, Zhang P, Zhang YY, Zhang QW, Chao ZH, et al. Glucoseregulated protein 78 and heparanase expression in oral squamous cell carcinoma: correlations and prognostic significance. World J Surg Oncol (2014) 12:121. doi:10.1186/1477-7819-12-121

83. Dos Santos TCF, Gomes AM, Paschoal MEM, Stelling MP, Rumjanek VMBD, Junior Ado R, et al. Heparanase expression and localization in different types of human lung cancer. Biochim Biophys Acta (2014) 1840:2599-608. doi:10.1016/j.bbagen.2014.04.010

84. Hoffmann A-C, Goekkurt E, Danenberg PV, Lehmann S, Ehninger G, Aust DE, et al. EGFR, FLT1 and heparanase as markers identifying patients at risk of short survival in cholangiocarcinoma. PLoS One (2013) 8:e64186. doi:10.1371/journal.pone.0064186

85. Beckhove P, Helmke BM, Ziouta Y, Bucur M, Dörner W, Mogler C, et al. Heparanase expression at the invasion front of human head and neck cancers and correlation with poor prognosis. Clin Cancer Res (2005) 11:2899-906. doi:10.1158/1078-0432.CCR-04-0664

86. Mogler C, Herold-Mende C, Dyckhoff G, Jenetzky E, Beckhove P, Helmke BM. Heparanase expression in head and neck squamous cell carcinomas is associated with reduced proliferation and improved survival. Histopathology (2011) 58:944-52. doi:10.1111/j.1365-2559.2011.03834.x

87. Kazarin O, Ilan N, Naroditzky I, Ben-Itzhak O, Vlodavsky I, Bar-Sela G. Expression of heparanase in soft tissue sarcomas of adults. J Exp Clin Cancer Res (2014) 33:39. doi:10.1186/1756-9966-33-39

88. Bitan M, Polliack A, Zecchina G, Nagler A, Friedmann Y, Nadav L, et al. Heparanase expression in human leukemias is restricted to acute myeloid leukemias. Exp Hematol (2002) 30:34-41. doi:10.1016/S0301472X(01)00766- 4

89. Ostrovsky O, Korostishevsky M, Levite I, Leiba M, Galski H, Vlodavsky I, et al. Association of heparanase gene (HPSE) single nucleotide polymorphisms with hematological malignancies. Leukemia (2007) 21:2296-303. doi:10.1038/sj.leu. 2404821

90. Hur K, Han T-S, Jung E-J, Yu J, Lee H-J, Kim WH, et al. Up-regulated expression of sulfatases (SULF1 and SULF2) as prognostic and metastasis predictive markers in human gastric cancer. J Pathol (2012) 228:88-98. doi:10.1002/path.4055

91. Gopal G, Shirley S, Raja UM, Rajkumar T. Endo-sulfatase Sulf-1 protein expression is down-regulated in gastric cancer. Asian Pac J Cancer Prev (2012) 13:641-6. doi:10.7314/APJCP.2012.13.2.641

92. Phillips JJ, Huillard E, Robinson AE, Ward A, Lum DH, Polley M-Y, et al. Heparan sulfate sulfatase SULF2 regulates PDGFR $\alpha$ signaling and growth 
in human and mouse malignant glioma. J Clin Invest (2012) 122:911-22. doi:10.1172/JCI58215

93. Bret C, Moreaux J, Schved J-F, Hose D, Klein B. SULFs in human neoplasia: implication as progression and prognosis factors. J Transl Med (2011) 9:72. doi:10.1186/1479-5876-9-72

94. Lui NS, van Zante A, Rosen SD, Jablons DM, Lemjabbar-Alaoui H. SULF2 expression by immunohistochemistry and overall survival in oesophageal cancer: a cohort study. BMJ Open (2012) 2:e01624. doi:10.1136/bmjopen-2012001624

95. Koliopanos A, Friess H, Kleeff J, Shi X, Liao Q, Pecker I, et al. Heparanase expression in primary and metastatic pancreatic cancer. Cancer Res (2001) 61:4655-9.

96. Rohloff J, Zinke J, Schoppmeyer K, Tannapfel A, Witzigmann H, Mössner $\mathrm{J}$, et al. Heparanase expression is a prognostic indicator for postoperative survival in pancreatic adenocarcinoma. Br J Cancer (2002) 86:1270-5. doi:10.1038/sj.bjc.6600232

97. Chen J, Lei C, DU M, Li W, Tang H. The clinical significance of heparanase expression in human pancreatic carcinoma tissue. Zhonghua Wai Ke Za Zhi (2008) 46:1502-4.

98. Quiros RM, Rao G, Plate J, Harris JE, Brunn GJ, Platt JL, et al. Elevated serum heparanase-1 levels in patients with pancreatic carcinoma are associated with poor survival. Cancer (2006) 106:532-40. doi:10.1002/cncr.21648

99. Iacobuzio-Donahue CA, Ashfaq R, Maitra A, Adsay NV, Shen-Ong GL, Berg K, et al. Highly expressed genes in pancreatic ductal adenocarcinomas: a comprehensive characterization and comparison of the transcription profiles obtained from three major technologies. Cancer Res (2003) 63:8614-22.

100. Li J, Kleeff J, Abiatari I, Kayed H, Giese NA, Felix K, et al. Enhanced levels of Hsulf-1 interfere with heparin-binding growth factor signaling in pancreatic cancer. Mol Cancer (2005) 4:14. doi:10.1186/1476-4598-4-14

101. Nawroth R, van Zante A, Cervantes S, McManus M, Hebrok M, Rosen SD. Extracellular sulfatases, elements of the Wnt signaling pathway, positively regulate growth and tumorigenicity of human pancreatic cancer cells. PLoS One (2007) 2:e392. doi:10.1371/journal.pone.0000392

102. El-Assal ON, Yamanoi A, Ono T, Kohno H, Nagasue N. The clinicopathological significance of heparanase and basic fibroblast growth factor expressions in hepatocellular carcinoma. Clin Cancer Res (2001) 7:1299-305.

103. Chen X-P, Liu Y-B, Rui J, Peng S-Y, Peng C-H, Zhou Z-Y, et al. Heparanase mRNA expression and point mutation in hepatocellular carcinoma. World $J$ Gastroenterol (2004) 10:2795-9.

104. Chen G, Dang Y-W, Luo D-Z, Feng Z-B, Tang X-L. Expression of heparanase in hepatocellular carcinoma has prognostic significance: a tissue microarray study. Oncol Res (2008) 17:183-9. doi:10.3727/096504008785114138

105. Wang G-B, Zhou X-Y, Wang X-Q. Relationship between serum heparanase and microscopic venous invasion in patients with hepatocellular carcinoma. Am J Clin Pathol (2010) 134:242-8. doi:10.1309/AJCPPJM6VHG4LPJX

106. Lai J-P, Yu C, Moser CD, Aderca I, Han T, Garvey TD, et al. SULF1 inhibits tumor growth and potentiates the effects of histone deacetylase inhibitors in hepatocellular carcinoma. Gastroenterology (2006) 130:2130-44. doi:10.1053/ j.gastro.2006.02.056

107. Yang JD, Sun Z, Hu C, Lai J, Dove R, Nakamura I, et al. Sulfatase 1 and sulfatase 2 in hepatocellular carcinoma: associated signaling pathways, tumor phenotypes, and survival. Genes Chromosomes Cancer (2011) 50:122-35. doi: $10.1002 /$ gcc. 20838

108. Lee J-S, Heo J, Libbrecht L, Chu I-S, Kaposi-Novak P, Calvisi DF, et al. A novel prognostic subtype of human hepatocellular carcinoma derived from hepatic progenitor cells. Nat Med (2006) 12:410-6. doi:10.1038/nm1377

109. Endo K, Maejara U, Baba H, Tokunaga E, Koga T, Ikeda Y, et al. Heparanase gene expression and metastatic potential in human gastric cancer. Anticancer Res (2001) 21:3365-9.

110. Takaoka M, Naomoto Y, Ohkawa T, Uetsuka H, Shirakawa Y, Uno F, et al. Heparanase expression correlates with invasion and poor prognosis in gastric cancers. Lab Invest (2003) 83:613-22. doi:10.1097/01.LAB.0000067482.84946. BD

111. Tang W, Nakamura Y, Tsujimoto M, Sato M, Wang X, Kurozumi K, et al. Heparanase: a key enzyme in invasion and metastasis of gastric carcinoma. Mod Pathol (2002) 15:593-8. doi:10.1038/modpathol.3880571

112. Wang Z, Zhang X, Xu H, Zhou X, Jiang L, Lu C. Detection of peritoneal micrometastasis by reverse transcriptase-polymerase chain reaction for heparanase mRNA and cytology in peritoneal wash samples. J Surg Oncol (2005) 90:59-65. doi:10.1002/jso.20250

113. Zheng L, Pu J, Jiang G, Weng M, He J, Mei H, et al. Abnormal expression of early growth response 1 in gastric cancer: association with tumor invasion, metastasis and heparanase transcription. Pathol Int (2010) 60:268-77. doi:10.1111/j.1440-1827.2010.02512.x

114. Sonoda R, Naomoto Y, Shirakawa Y, Fujiwara Y, Yamatsuji T, Noma K, et al. Preferential up-regulation of heparanase and cyclooxygenase- 2 in carcinogenesis of Barrett's oesophagus and intestinal-type gastric carcinoma. Histopathology (2010) 57:90-100. doi:10.1111/j.1365-2559.2010.03594.x

115. Cheng C, Lu X, Wang G, Zheng L, Shu X, Zhu S, et al. Expression of SATB1 and heparanase in gastric cancer and its relationship to clinicopathologic features. APMIS (2010) 118:855-63. doi:10.1111/j.1600-0463.2010.02673.x

116. Li J, Mo M-L, Chen Z, Yang J, Li Q-S, Wang D-J, et al. HSulf- 1 inhibits cell proliferation and invasion in human gastric cancer. Cancer Sci (2011) 102:1815-21. doi:10.1111/j.1349-7006.2011.02024.x

117. Ma H-Y, Zhang F, Li J, Mo M-L, Chen Z, Liu L, et al. HSulf-1 suppresses cell growth and down-regulates Hedgehog signaling in human gastric cancer cells. Oncol Lett (2011) 2:1291-5. doi:10.3892/ol.2011.407

118. Doweck I, Kaplan-Cohen V, Naroditsky I, Sabo E, Ilan N, Vlodavsky I. Heparanase localization and expression by head and neck cancer: correlation with tumor progression and patient survival. Neoplasia (2006) 8:1055-61. doi:10.1593/neo.06577

119. Tang D, Zhang Q, Zhao S, Wang J, Lu K, Song Y, et al. The expression and clinical significance of microRNA-1258 and heparanase in human breast cancer. Clin Biochem (2013) 46:926-32. doi:10.1016/j.clinbiochem.2013.01.027

120. Fernández-Vega I, García O, Crespo A, Castañón S, Menéndez P, Astudillo A, et al. Specific genes involved in synthesis and editing of heparan sulfate proteoglycans show altered expression patterns in breast cancer. BMC Cancer (2013) 13:24. doi:10.1186/1471-2407-13-24

121. Ridgway LD, Wetzel MD, Ngo JA, Erdreich-Epstein A, Marchetti D. Heparanase-induced GEF-H1 signaling regulates the cytoskeletal dynamics of brain metastatic breast cancer cells. Mol Cancer Res (2012) 10:689-702. doi:10.1158/1541-7786.MCR-11-0534

122. Khurana A, Jung-Beom D, He X, Kim S-H, Busby RC, Lorenzon L, et al. Matrix detachment and proteasomal inhibitors diminish Sulf-2 expression in breast cancer cell lines and mouse xenografts. Clin Exp Metastasis (2013) 30:407-15. doi:10.1007/s10585-012-9546-5

123. Liu P, Khurana A, Rattan R, He X, Kalloger S, Dowdy S, et al. Regulation of HSulf-1 expression by variant hepatic nuclear factor 1 in ovarian cancer. Cancer Res (2009) 69:4843-50. doi:10.1158/0008-5472.CAN-08-3065

124. Liu P, Gou M, Yi T, Qi X, Xie C, Zhou S, et al. The enhanced antitumor effects of biodegradable cationic heparin-polyethyleneimine nanogels delivering HSulf-1 gene combined with cisplatin on ovarian cancer. Int J Oncol (2012) 41:1504-12. doi:10.3892/ijo.2012.1558

125. Cole CL, Rushton G, Jayson GC, Avizienyte E. Ovarian cancer cell heparan sulfate 6-O-sulfotransferases regulate an angiogenic program induced by heparin-binding epidermal growth factor (EGF)-like growth factor/EGF receptor signaling. J Biol Chem (2014) 289:10488-501. doi:10.1074/jbc.M113. 534263

126. Liu H, Chen X, Gao W, Jiang G. The expression of heparanase and microRNA1258 in human non-small cell lung cancer. Tumour Biol (2012) 33:1327-34 doi:10.1007/s13277-012-0380-9

127. Lemjabbar-Alaoui H, van Zante A, Singer MS, Xue Q, Wang Y-Q, Tsay D, et al. Sulf-2, a heparan sulfate endosulfatase, promotes human lung carcinogenesis. Oncogene (2010) 29:635-46. doi:10.1038/onc.2009.365

128. Ruan J, Trotter TN, Nan L, Luo R, Javed A, Sanderson RD, et al. Heparanase inhibits osteoblastogenesis and shifts bone marrow progenitor cell fate in myeloma bone disease. Bone (2013) 57:10-7. doi:10.1016/j.bone.2013 07.024

129. Barash U, Zohar Y, Wildbaum G, Beider K, Nagler A, Karin N, et al. Heparanase enhances myeloma progression via CXCL10 downregulation. Leukemia (2014). doi:10.1038/leu.2014.121

130. Miao H-Q, Liu H, Navarro E, Kussie P, Zhu Z. Development of heparanase inhibitors for anti-cancer therapy. Curr Med Chem (2006) 13:2101-11. doi:10. 2174/092986706777935230

131. McKenzie EA. Heparanase: a target for drug discovery in cancer and inflammation. Br J Pharmacol (2007) 151:1-14. doi:10.1038/sj.bjp.0707182 
132. Ferro V, Li C, Fewings K, Palermo MC, Linhardt RJ, Toida T. Determination of the composition of the oligosaccharide phosphate fraction of Pichia (Hansenula) holstii NRRL Y-2448 phosphomannan by capillary electrophoresis and HPLC. Carbohydr Res (2002) 337:139-46. doi:10.1016/S0008-6215(01) 00300-7

133. Kudchadkar R, Gonzalez R, Lewis KD. PI-88: a novel inhibitor of angiogenesis. Expert Opin Investig Drugs (2008) 17:1769-76. doi:10.1517/13543784.17.11. 1769

134. Parish CR, Freeman C, Brown KJ, Francis DJ, Cowden WB. Identification of sulfated oligosaccharide-based inhibitors of tumor growth and metastasis using novel in vitro assays for angiogenesis and heparanase activity. Cancer Res (1999) 59:3433-41.

135. Joyce JA, Freeman C, Meyer-Morse N, Parish CR, Hanahan D. A functional heparan sulfate mimetic implicates both heparanase and heparan sulfate in tumor angiogenesis and invasion in a mouse model of multistage cancer. Oncogene (2005) 24:4037-51. doi:10.1038/sj.onc. 1208602

136. Iversen PO, Sorensen DR, Benestad HB. Inhibitors of angiogenesis selectively reduce the malignant cell load in rodent models of human myeloid leukemias. Leukemia (2002) 16:376-81. doi:10.1038/sj.leu.2402376

137. Medigen Biotechnology Corporation. A phase III study of PI- 88 in the adjuvant treatment of subjects with hepatitis virus related hepatocellular carcinoma after surgical resection (PATRON). In: ClinicalTrials.gov [Internet]. Bethesda (MD): National Library of Medicine (US); 2000 [cited 2014 June 3]. Available from: https://clinicaltrials.gov/ct2/show/NCT01402908

138. Pan W, Miao H-Q, Xu Y-J, Navarro EC, Tonra JR, Corcoran E, et al. 1-[4-(1H-benzoimidazol-2-yl)-phenyl]-3-[4-(1H-benzoimidazol-2-yl)phenyl]-urea derivatives as small molecule heparanase inhibitors. Bioorg Med Chem Lett (2006) 16:409-12. doi:10.1016/j.bmcl.2005.09.069

139. Ayal-Hershkovitz M, Levy O, Miron D, Inventors; Insight Strategy And Marketing, assignee. Indole Derivatives and Their Uses as Heparanase Inhibitors. PCT patent application. WO 2002060373 A2 (2002).

140. Ayal-Hershkovitz M, Levy O, Miron D, Inventors; Insight Strategy And Marketing, assignee. Benz-1,3-azole Derivatives and Their Uses as Heparanase Inhibitors. PCT patent application. WO 2002060374 A2 (2002).

141. Ayal-Hershkovitz M, Ilan N, Koller A, Levy O, Miron D, Inventors; Insight Strategy And Marketing, assignee. Diphenyl Ether Derivatives and Their Uses as Heparanase Inhibitors. PCT patent application. WO 2002060375 A2 (2002).

142. Ayal-Hershkovitz M, Ilan N, Koller A, Levy O, Miron D, Inventors; Insight Strategy And Marketing, assignee. Carbazole Derivatives and Their Uses as Heparanase Inhibitors. PCT patent application. WO 2002060867 A2 (2002).

143. Rathanaswami P, Pan O, Ross S, King C, Foltz IN, Elvin P. Abstract 558: targeting tumour heparanase activity using fully human monoclonal antibodies. Cancer Res (2011) 71:558-558. doi:10.1158/1538-7445.AM2011-558

144. Nancy-Portebois V, Cabannes E, Petitou M, Serin G, Mirjolet J-F. Abstract 5459: antitumor activity of EP80061, a small-glyco drug in preclinical studies. Cancer Res (2011) 70:5459-5459. doi:10.1158/1538-7445.AM10-5459

145. Zhao H, Liu H, Chen Y, Xin X, Li J, Hou Y, et al. Oligomannurarate sulfate, a novel heparanase inhibitor simultaneously targeting basic fibroblast growth factor, combats tumor angiogenesis and metastasis. Cancer Res (2006) 66:8779-87. doi:10.1158/0008-5472.CAN-06-1382

146. Li Q-N, Liu H-Y, Xin X-L, Pan Q-M, Wang L, Zhang J, et al. Marinederived oligosaccharide sulfate (JG3) suppresses heparanase-driven cell adhesion events in heparanase over-expressing CHO-K1 cells. Acta Pharmacol Sin (2009) 30:1033-8. doi:10.1038/aps.2009.97

147. Ishida K, Teruya T, Simizu S, Osada H. Exploitation of heparanase inhibitors from microbial metabolites using an efficient visual screening system. JAntibiot (Tokyo) (2004) 57:136-42. doi:10.7164/antibiotics.57.136

148. Ishida K, Wierzba MK, Teruya T, Simizu S, Osada H. Novel heparan sulfate mimetic compounds as antitumor agents. Chem Biol (2004) 11:367-77. doi:10.1016/j.chembiol.2004.02.015

149. Hammond E, Handley P, Dredge K, Bytheway I. Mechanisms of heparanase inhibition by the heparan sulfate mimetic PG545 and three structural analogues. FEBS Open Bio (2013) 3:346-51. doi:10.1016/j.fob.2013.07.007

150. Dredge K, Hammond E, Davis K, Li CP, Liu L, Johnstone K, et al. The PG500 series: novel heparan sulfate mimetics as potent angiogenesis and heparanase inhibitors for cancer therapy. Invest New Drugs (2010) 28:276-83. doi:10.1007/s10637-009-9245-5
151. Dredge K, Hammond E, Handley P, Gonda TJ, Smith MT, Vincent C, et al. PG545, a dual heparanase and angiogenesis inhibitor, induces potent antitumour and anti-metastatic efficacy in preclinical models. Br J Cancer (2011) 104:635-42. doi:10.1038/bjc.2011.11

152. Hammond E, Brandt R, Dredge K. PG545, a heparan sulfate mimetic, reduces heparanase expression in vivo, blocks spontaneous metastases and enhances overall survival in the $4 \mathrm{~T} 1$ breast carcinoma model. PLoS One (2012) 7:e52175. doi:10.1371/journal.pone.0052175

153. Progen Pharmaceuticals. Study of the safety and tolerability of IV infused PG545 in patients with advanced solid tumours. In: ClinicalTrials.gov [Internet]. Bethesda (MD): National Library of Medicine (US); 2000 [cited 2014 June 3]. Available from: https://clinicaltrials.gov/ct2/show/NCT02042781

154. Zhou H, Roy S, Cochran E, Zouaoui R, Chu CL, Duffner J, et al. M402, a novel heparan sulfate mimetic, targets multiple pathways implicated in tumor progression and metastasis. PLoS One (2011) 6:e21106. doi:10.1371/journal.pone. 0021106

155. Momenta Pharmaceuticals. M402 in combination with Nab-paclitaxel and gemcitabine in pancreatic cancer. In: ClinicalTrials.gov [Internet]. Bethesda (MD): National Library of Medicine (US); 2000 [cited 2014 June 3]. Available from: https://clinicaltrials.gov/ct2/show/NCT01621243

156. Ritchie JP, Ramani VC, Ren Y, Naggi A, Torri G, Casu B, et al. SST0001, a chemically modified heparin, inhibits myeloma growth and angiogenesis via disruption of the heparanase/syndecan-1 axis. Clin Cancer Res (2011) 17:1382-93. doi:10.1158/1078-0432.CCR-10-2476

157. SigmaTau Research. SST0001 in advanced multiple myeloma. In: ClinicalTrials.gov [Internet]. Bethesda (MD): National Library of Medicine (US); 2000 [cited 2014 June 3]. Available from: https://clinicaltrials.gov/ct2/show/ NCT01764880

158. Courtney SM, Hay PA, Buck RT, Colville CS, Porter DW, Scopes DIC, et al. 2,3Dihydro-1,3-dioxo-1H-isoindole-5-carboxylic acid derivatives: a novel class of small molecule heparanase inhibitors. Bioorg Med Chem Lett (2004) 14:3269-73. doi:10.1016/j.bmcl.2004.03.086

159. Courtney SM, Hay PA, Buck RT, Colville CS, Phillips DJ, Scopes DIC, et al. Furanyl-1,3-thiazol-2-yl and benzoxazol-5-yl acetic acid derivatives: novel classes of heparanase inhibitor. Bioorg Med Chem Lett (2005) 15:2295-9. doi:10.1016/j.bmcl.2005.03.014

160. Xu Y-J, Miao H-Q, Pan W, Navarro EC, Tonra JR, Mitelman S, et al. N-(4$\{[4$-(1H-benzoimidazol-2-yl)-arylamino]-methyl $\}$-phenyl)-benzamide derivatives as small molecule heparanase inhibitors. Bioorg Med Chem Lett (2006) 16:404-8. doi:10.1016/j.bmcl.2005.09.070

161. Li Y, Liu H, Huang YY, Pu LJ, Zhang XD, Jiang CC, et al. Suppression of endoplasmic reticulum stress-induced invasion and migration of breast cancer cells through the downregulation of heparanase. Int J Mol Med (2013) 31:1234-42. doi:10.3892/ijmm.2013.1292

162. Li Y, Liu H, Huang Y-Y, Pu L-J, Zhang X-D, Jiang Z-W, et al. Effects of cisplatin combined with heparanase inhibitor on proliferation and invasion of human nasopharyngeal carcinoma cells. Yao Xue Xue Bao (2013) 48: 609-14.

163. Nadanaka S, Purunomo E, Takeda N, Tamura J-I, Kitagawa H. Heparan sulfate containing unsubstituted glucosamine residues: biosynthesis and heparanase inhibitory activity. J Biol Chem (2014) 289:15231-43. doi:10.1074/ jbc.M113.545343

164. Roy S, El Hadri A, Richard S, Denis F, Holte K, Duffner J, et al. Synthesis and biological evaluation of a unique heparin mimetic hexasaccharide for structure-activity relationship studies. J Med Chem (2014) 57:4511-20. doi:10.1021/jm4016069

165. Dai Y, Yang Y, MacLeod V, Yue X, Rapraeger AC, Shriver Z, et al. HSulf-1 and HSulf-2 are potent inhibitors of myeloma tumor growth in vivo. $J$ Biol Chem (2005) 280:40066-73. doi:10.1074/jbc.M508136200

166. Hossain MM, Hosono-Fukao T, Tang R, Sugaya N, van Kuppevelt TH, Jenniskens GJ, et al. Direct detection of HSulf-1 and HSulf-2 activities on extracellular heparan sulfate and their inhibition by PI-88. Glycobiology (2010) 20:175-86. doi:10.1093/glycob/cwp159

167. Liu H, Fu X, Ji W, Liu K, Bao L, Yan Y, et al. Human sulfatase-1 inhibits the migration and proliferation of SMMC-7721 hepatocellular carcinoma cells by downregulating the growth factor signaling. Hepatol Res (2013) 43:516-25. doi:10.1111/j.1872-034X.2012.01080.x 
168. Khurana A, McKean H, Kim H, Kim S-H, Mcguire J, Roberts LR, et al. Silencing of HSulf-2 expression in MCF10DCIS.com cells attenuate ductal carcinoma in situ progression to invasive ductal carcinoma in vivo. Breast Cancer Res (2012) 14:R43. doi: $10.1186 / \mathrm{bcr} 3140$

169. Zheng X, Gai X, Han S, Moser CD, Hu C, Shire AM, et al. The human sulfatase 2 inhibitor 2,4-disulfonylphenyl-tert-butylnitrone (OKN-007) has an antitumor effect in hepatocellular carcinoma mediated via suppression of TGFB1/SMAD2 and Hedgehog/GLI1 signaling. Genes Chromosomes Cancer (2013) 52:225-36. doi:10.1002/gcc. 22022

Conflict of Interest Statement: Keith Dredge and Edward Hammond are employees of Progen Pharmaceuticals and are actively involved in the development of one of the experimental agents discussed in this review, PG545. The other co-authors report no conflicts of interest.
Received: 10 June 2014; paper pending published: 26 June 2014; accepted: 10 July 2014; published online: 24 July 2014.

Citation: Hammond E, Khurana A, Shridhar V and Dredge K (2014) The role of heparanase and sulfatases in the modification of heparan sulfate proteoglycans within the tumor microenvironment and opportunities for novel cancer therapeutics. Front. Oncol. 4:195. doi: 10.3389/fonc.2014.00195

This article was submitted to Molecular and Cellular Oncology, a section of the journal Frontiers in Oncology.

Copyright (c) 2014 Hammond, Khurana, Shridhar and Dredge. This is an open-access article distributed under the terms of the Creative Commons Attribution License (CC $B Y)$. The use, distribution or reproduction in other forums is permitted, provided the original author(s) or licensor are credited and that the original publication in this journal is cited, in accordance with accepted academic practice. No use, distribution or reproduction is permitted which does not comply with these terms. 